\title{
LEARNING FROM RESULTS-BASED MANAGEMENT EVALUATIONS AND REVIEWS
}

Janet Vähämäki and Chantal Verger

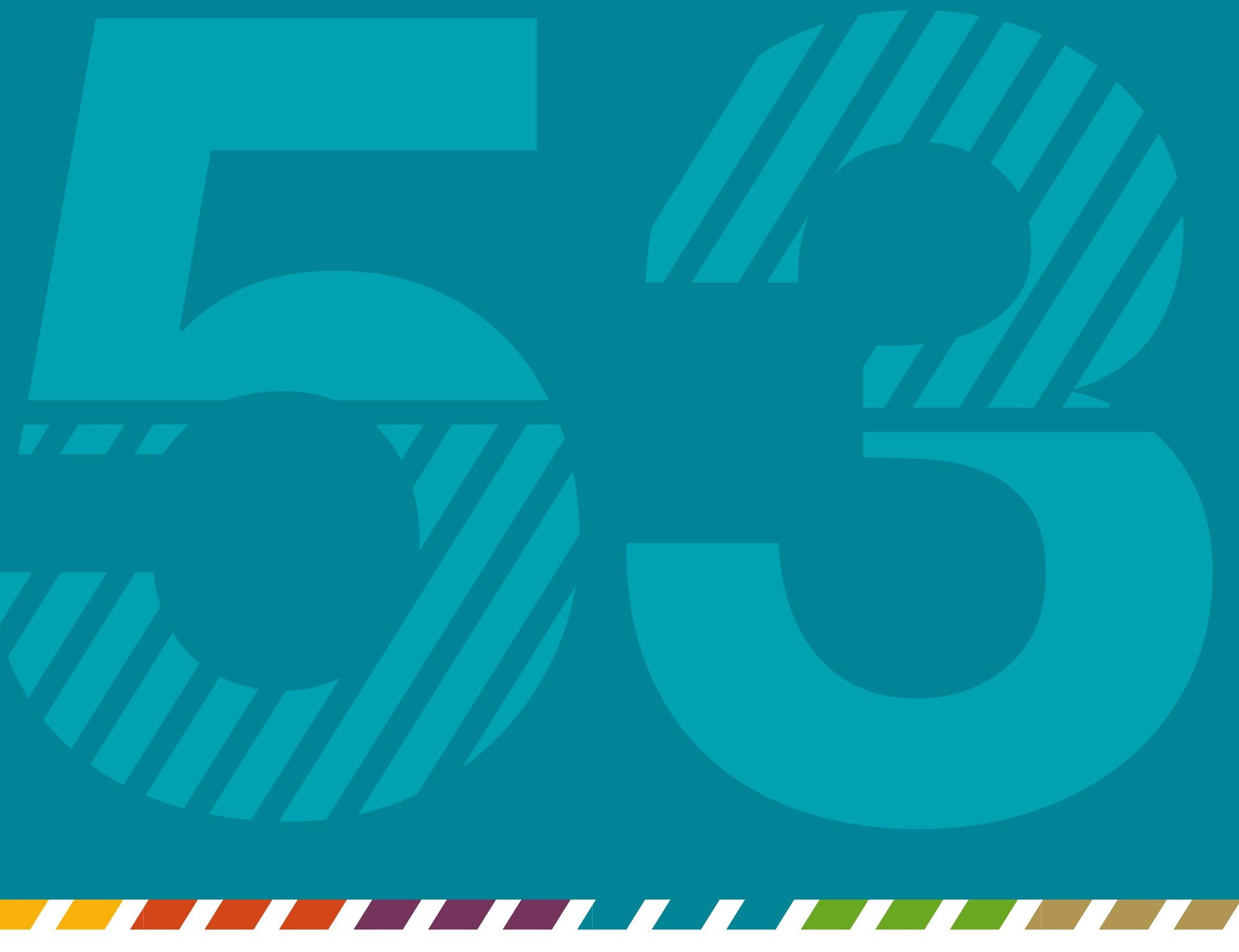

OECD DEVELOPMENT CO-OPERATION WORKING PAPER 53

Authorised for publication by Jorge Moreira da Silva, Director, Development Co-operation Directorate 



\title{
Learning from Results-Based Management evaluations and reviews
}

\begin{abstract}
What have we learned from implementing results-based management in development co-operation organisations? What progress and benefits can be seen? What are the main challenges and unintended consequences? Are there good practices to address these challenges?

To respond to these questions this paper reviews and analyses the findings from various evaluations and reviews of results-based management systems conducted by members of the Development Assistance Committee (DAC), the OECD/DAC Results Community Secretariat and other bodies in the past four years (2015-2018). It also draws on emerging lessons from new methods for managing development co-operation results.

This analytical work aims to:

i. identify recent trends in results-based management,

ii. explore challenges faced by providers when developing their results approaches and systems,

iii. select good practices in responding to these challenges that can be useful for the OECD/DAC Results Community, considering new approaches, new technologies and evolving contexts.
\end{abstract}

This body of evidence will inform the development of a core set of generic guiding principles for resultsbased management in development co-operation.

\section{Acknowledgements}

This paper is based on work done by Janet Vähämäki, Researcher, under the strategic guidance and oversight of Chantal Verger, Head of the Results team, OECD Development Co-operation Directorate, who finalised the report. A preliminary version was presented and discussed at a Workshop of the OECD/DAC Results Community on 30 October 2018. The paper was reviewed by members of the reference group that accompanies the project: Mari Räkköläinen (Ministry for Foreign Affairs, Finland), Suvi Virkkunen (Ministry for Foreign Affairs, Finland), Marianne Skaiaa (Norway), Pradeep Itty (Switzerland), Elizabeth Roen (United States), Samer Hachem (MOPAN Secretariat) and Sukai Prom-Jakson (UN Joint Inspection Unit), as well as by Rosie Zwart from the Results team. The report has been edited by Ola Kasneci from the Results Community Secretariat. 


\section{OECD DEVELOPMENT CO-OPERATION WORKING PAPERS}

This paper does not represent the official views of the OECD or of its member countries. The opinions expressed and arguments employed are those of the authors.

Working Papers describe preliminary results or research in progress by the author(s) and are published to stimulate discussion on a broad range of issues on which the OECD works. Comments on the present Working Paper are welcomed and may be sent to Chantal.Verger@oecd.org - the Development Cooperation Directorate, OECD, 2 rue André Pascal, 75775 Paris Cedex 16, France.

This document and any map included herein are without prejudice to the status of or sovereignty over any territory, to the delimitation of international frontiers and boundaries and to the name of any territory, city or area.

You can copy, download or print OECD content for your own use, and you can include excerpts from OECD publications, databases and multimedia products in your own documents, presentations, blogs, websites and teaching materials, provided that suitable acknowledgement of OECD as source and copyright owner is given. All requests for public or commercial use and translation rights should be submitted to rights@oecd.org.

\section{COPYRIGHT @ OECD 2019}

\section{Keywords:}

Results; results-based management; results framework; development co-operation; adaptive management; data; payment by results; evidence-based; Agenda 2030; SDGs; standard indicators; aggregation; performance measurement

\section{JEL codes:}

O19 International linkages to Development; O2 Development Planning and Policy; O20 General; O21 Planning Models, Planning Policy; Z18 Public Policy 


\section{Table of Contents}

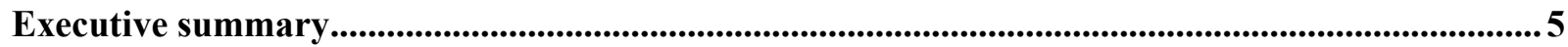

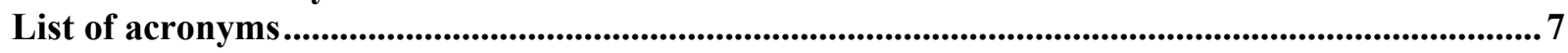

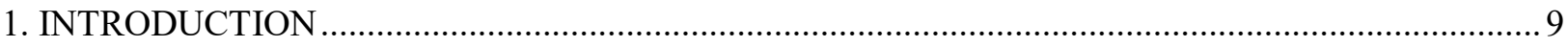

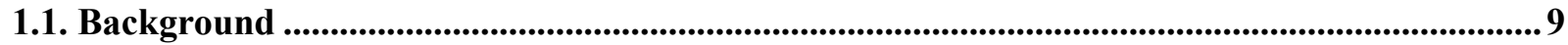

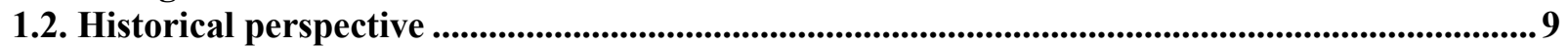

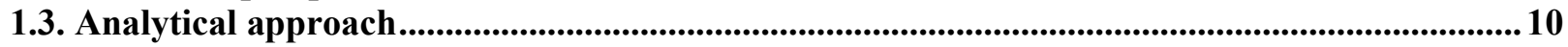

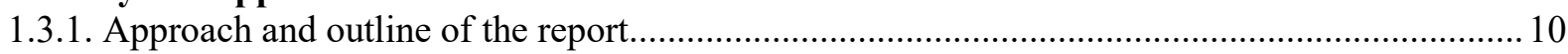

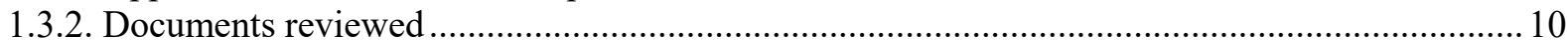

2. STATE OF PLAY - FINDINGS FROM THE REVIEWED DOCUMENTS........................................ 12

2.1. The purpose of results-based management ..............................................................................................12

2.2. Progress made: what has improved and how is results information used? ...................................14

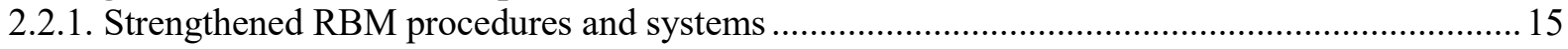

2.2.2. Progress in tracking outputs and short-term outcomes............................................................. 16

2.2.3. Better use of results information for reporting and domestic accountability ............................. 17

2.2.4. Uneven progress on use of results for decision-making and learning ...................................... 18

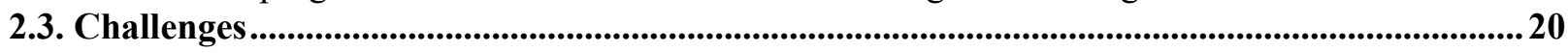

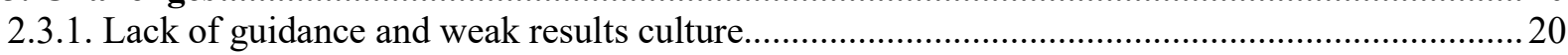

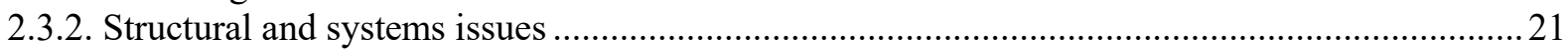

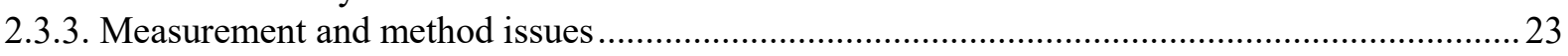

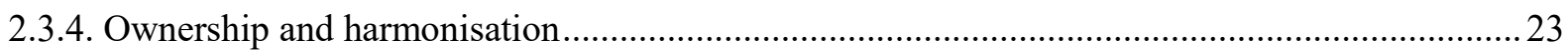

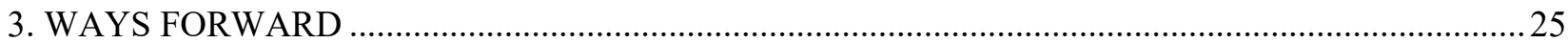

3.1. A changing development co-operation context ................................................................................25

3.2. Suggested solutions to the challenges and unintended consequences............................................26

3.3. New approaches .....................................................................................................................................................2 27

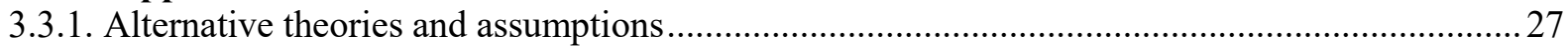

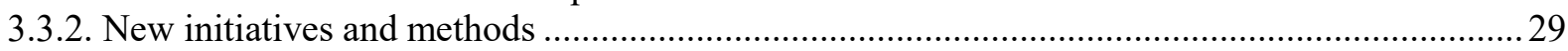

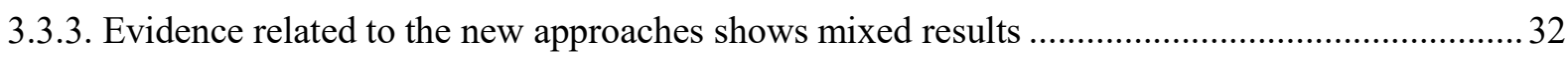

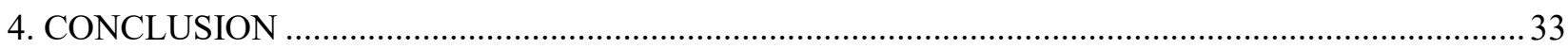

4.1. Adapting the management model to each context and authorising environment........................33

4.2. Getting the right narrative and enhancing communication...................................................34

4.3. Balancing the various objectives of results-based management ........................................................35

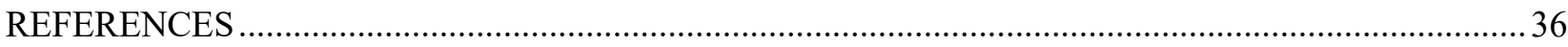

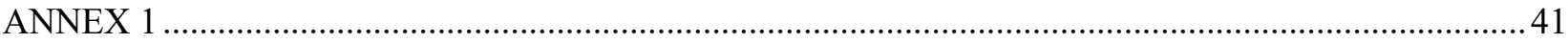

\section{Table of Boxes \& Tables}

Box 1: Criteria and process for selecting the documents ..................................................... 11

Box 2: Learning from RBM evaluations - experience from Finland ......................................... 15

Box 3: Unintended consequence - 1. Measure fixation: focus on what can be measured easily .... 17

Box 4: Evaluations are used for programming and learning ............................................... 18

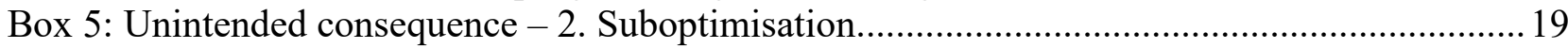

Box 6: Unintended consequence - 3. Counterproductive implementation..................................22

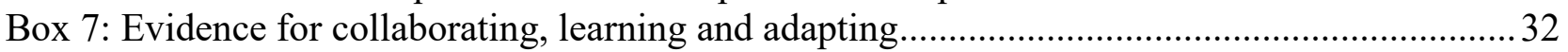


Table 1. Purpose of results-based management 13

Table 2. Solutions and recommendations to RBM challenges and unintended consequences........27

Table 3. Assumptions underpinning approaches to aid management ..........................................28

Table 4. Global initiatives working with adaptive management ............................................... 30 


\section{Executive summary}

The ultimate purpose of development co-operation is to achieve results, which means to bring tangible and sustainable change for people, societies and the environment. For this to happen, results-based management calls for development actors to set clear objectives with expected results, targets and indicators, and a system to measure how they are performing against their goals. They also need to use the information generated on performance and development co-operation results for accountability and communication as well as for decision-making and learning.

What have we learned from implementing results-based management in development co-operation organisations over the last 20 years? What progress and benefits can be seen? What are the main challenges and unintended consequences? Are there good practices to address these challenges?

This paper summarises and analyses findings on progress, challenges and unintended consequences from the implementation of results-based management (RBM) in development co-operation. The review draws primarily on findings from various evaluations and reviews of RBM systems conducted by members of the Development Assistance Committee (DAC), the OECD Secretariat and other bodies in the past four years (2015-2018). It also compares these findings with earlier studies, and draws on emerging lessons from new methods for managing development co-operation that are being undertaken by a number of institutions and global initiatives.

The review of recent evaluations reveal both areas of progress and remaining challenges, as follows:

- Providers have made progress in integrating RBM in their internal systems (planning, implementation and reporting). As a result, they are better equipped to monitor and report on output data and short-term outcome data, and they are increasingly using results data for communication and domestic accountability purposes.

- While some evidence points to a positive correlation between the quality of monitoring and evaluation at project level and ratings on project outcomes, uneven progress is noted on the use of results information for direction and learning. This might reduce the potential contribution of RBM to development results - an area which should be explored further.

- Challenges noted with RBM implementation, often already mentioned in earlier RBM reviews, relate to strategic, organisational and technical management dimensions. They include: i) insufficient guidance and incentives on RBM which, combined with the lack of a results culture, leads staff to interpret and apply RBM in inconsistent ways; ii) structural and system issues affecting the results chain; iii) capacity constraints; iv) measurement and method issues, making it difficult to assess how interventions contribute to development results; and v) limited uptake of the ownership and harmonisation dimensions in partner countries, running against recent commitments to support and use country-led results data.

- The review also identified three unintended consequences that were not foreseen and limit the potential of RBM. Providers tend to: i) prioritise what can be measured easily (measure fixation); ii) pursue the purpose of accountability at the expense of learning and policy direction (suboptimisation); and iii) become overly bureaucratic and rigid, thereby increasing transaction costs and hampering innovation (counter-productive implementation).

These challenges and unintended consequences become more acute when an organisation has not communicated clearly the purpose of its results approach and system. However, the reviews and evaluations do not lead organisations to dramatically reconsider the RBM approach; recommendations rather aim at improving how the approach works in practice (for example, through improved guidance and training). 
Meanwhile a number of initiatives aim to develop or pilot management tools that promote adaptability and learning to address complexity. These are based on approaches that focus on how problems are understood and how evidence and learning are used to solve these problems. While these approaches are sometimes presented as "alternatives" to RBM, the review actually shows that learning, ownership and adaptation were key features of RBM approaches, in particular as they were developed at the time of the Paris Declaration on Aid Effectiveness (2005). The renewed emphasis put on these aspects is useful as RBM practice has in some instances narrowed to performance-based approaches and needs to evolve in better responding to the new development context that involves dealing with complexity and multiple types of partnerships.

Adapting to local contexts and being flexible enough to respond to changes and performance feedback requires: i) focusing on better understanding the local context; ii) tailoring interventions to local context during project design; and iii) adapting interventions as the context evolves. While the expected outcomes are kept unchanged, the path towards reaching them (and therefore the outputs) can evolve where needed. This implies delegating further authority at the field level.

Adaptive management is also important at corporate level. A theory of change capturing how different aid channels and instruments contribute to the overall objectives set for the development co-operation policy can support a greater understanding of the results chain. While there is not a "one-size-fits-all" approach given that organisations operate in various environments and are subject to different governing processes, there are essential elements of RBM systems such as: a clear purpose for RBM, theory(ies) of change, results frameworks, monitoring and evaluation processes, documented feedback loops and related decision-making and reporting processes, knowledge management and learning systems, as well as staff incentives. These building blocks, informed by lessons from the reviews and alternative approaches, along with the principles that should underpin all results approaches (e.g. ownership and alignment) will be combined to constitute the core guiding principles for RBM in development co-operation that will be developed later in 2019. 


\section{List of acronyms}

ADAPT

CLA

CLEAR

CSOs

DAC

DDD

Dev Com

DFID

EU

GAO

GDI

GEF

GLAM

GPSA

ICAI

IEG

International IDEA

JIU

MOPAN

$\mathrm{M} \& \mathrm{E}$

M4R

MFA

MfDR

Norad

ODA

ODI

OECD

$\mathrm{PbR}$

PDIA

PMIS

RBM

SCORE

SDC

SDGs
Analysis driven agile programming techniques

Collaborating, Learning and Adapting

Centers for Learning on Evaluation and Results

Civil society organisations

Development Assistance Committee

Doing Development Differently initiative

OECD Development Communications Network

United Kingdom Department for International Development

European Union

United States Government Accountability Office

Global Delivery Initiative

Global Environment Facility

The Global Learning for Adaptive Management Initiative

Global Partnership for Social Accountability

Independent Commission for Aid Impact

Independent Evaluation Group

International Institute for Democracy and Electoral Assistance

Joint Inspection Unit of the United Nations System

Multilateral Organisation Performance Assessment Network

Monitoring and Evaluation

Managing for Results

Ministry of Foreign Affairs

Managing for Development Results

Norwegian Agency for Development Cooperation

Official Development Assistance

Overseas Development Institute

Organisation for Economic Co-operation and Development

Payment by results

Problem Driven Iterative Approach

Project Management Information System

Results-based management

Stockholm Center for Organisational Research

Swiss Agency for Development and Cooperation

Sustainable Development Goals 
8 | LEARNING FROM RESULTS-BASED MANAGEMENT EVALUATIONS AND REVIEWS

Sida

TA LEARN

TWP

USAID

WB
Swedish International Development Cooperation Agency

Transparency and Accountability Initiative

Thinking and Working Politically

United States Agency for International Development

The World Bank 


\section{Introduction}

\subsection{Background}

This paper is a review and analysis of progress in results-based management (RBM) in development cooperation. Drawing on findings from various evaluations and reviews of RBM systems conducted by members of the Development Assistance Committee (DAC), the OECD Secretariat and other bodies in the past four years (2015-2018), this analytical work aims to:
i. identify recent trends in RBM,
ii. explore challenges faced by providers when developing their results approaches and systems,
iii. select good practices in responding to these challenges that can be useful for the Results Community ${ }^{1}$, considering new approaches, new technologies and evolving contexts.

The review is part of a broader project entitled "Learning from evaluations and reviews of RBM approaches and systems - Development of guiding principles" led by the OECD/DAC Results team. The paper addresses the following questions: What have we learned from implementing RBM in development co-operation organisations? What progress and benefits can be seen? What are the main challenges and unintended consequences? Are there good practices to respond to these challenges? What could be done differently?

\subsection{Historical perspective}

The term results-based management was first used in the 1990s. It originates from concepts such as management by results or management by objectives commonly used in other policy areas since the 1960s. RBM was broadly launched in many aid agencies in the 1990s, as a "management strategy aimed at achieving important changes in the way government agencies operate, with improving performance (achieving better results) as the central orientation" (Binnedjikt, 2000:6). The fundamental idea was that the generation of performance information would support accountability reporting to external stakeholder audiences and be used for internal management learning and decision-making. A core idea was delegation as well as participative management, i.e. that RBM would empower staff and teams to come up with their own approaches to achieving results. Flexibility to experiment, innovate, adapt and learn was seen as a core element of the approach (Binnedjikt, 2000; Hummelbrunner \& Jones, 2013).

The 2002 OECD DAC Glossary of key terms in evaluation and results-based management has a relatively narrow definition of RBM as "a management strategy focusing on performance and achievement of outputs, outcomes and impact" (OECD, 2002). In the early 2000s, however, an enlarged results focus in development co-operation was vividly discussed in the high-level roundtables that led to the 2005 Paris Declaration on aid effectiveness, during which related norms and principles were developed. As a result, when defining Managing for Development Results (MfDR) in 2006, the OECD assumed that: "global development assistance can be made more effective by enhancing country ownership, aligning assistance with country priorities, harmonizing development agencies' policies and procedures, and focusing more consistently on the achievement of development outcomes" (OECD, 2006). MfDR came with five principles:

1. Focus the dialogue on results at all phases of the development process

2. Aligning programming, monitoring, and evaluation with results

3. Keeping measurement and reporting simple

4. Managing for, not by, results

5. Using results information for learning and decision making.

\footnotetext{
${ }^{1}$ See http://www.oecd.org/dac/results-development/results-community.htm for more information.
} 
The focus in the MfDR process was thus on ownership and use of results for learning and decision-making, shifting from the earlier focus on accountability. The MfDR Sourcebook stressed that no penalties would apply for missed targets and encouraged a flexible approach to analysing reasons for failure to inform adaptation. It provided several examples of how adaptation and learning from results had led to the achievement of development results.

Other handbooks such as the 2004 World Bank "Ten Steps to Results Based Monitoring and Evaluation" emphasised the need to set goals, outcomes, indicators and targets and have a baseline. Meanwhile the handbook also stressed the importance of involving many actors with a participatory approach when defining problems and setting goals to ensure ownership on the part of the main internal and external stakeholders. It also brought up the importance of adaptation to changes in legislative and organisational priorities. However, it also argued that despite these changes, maintaining indicator stability over time was important to ensure comparability (Kusek and Rist, 2004). Consistency in measurement was thus seen as more important than continuous adaptation.

\subsection{Analytical approach}

\subsubsection{Approach and outline of the report}

Figure 1, below, illustrates the analytical approach putting in perspective the overall objective of RBM, its various purpose, and ways in which implementation happens and affects the purpose.

Figure 1. RBM objective, purpose and implementation
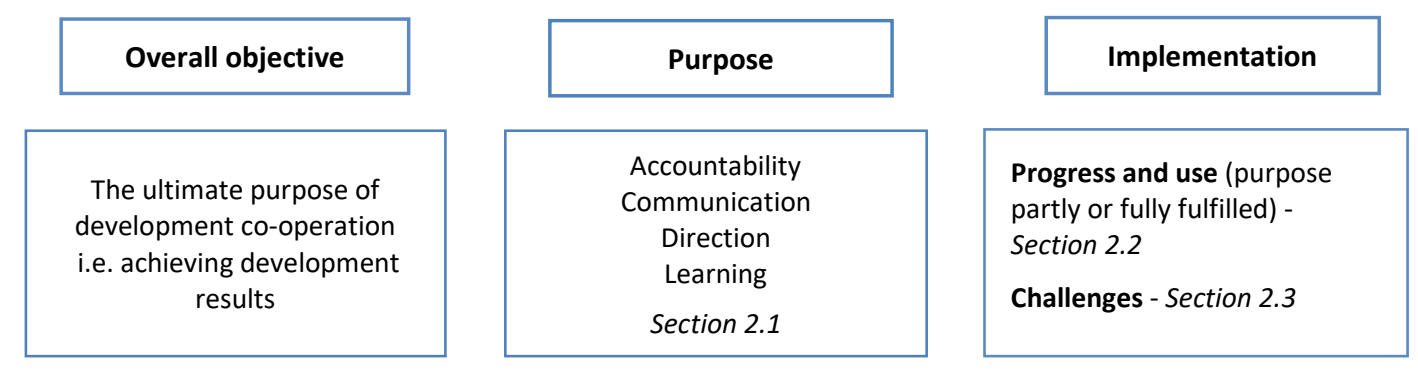

As shown in the figure, the overall objective of results-based management should be the same as the ultimate purpose of development co-operation, since it is a management strategy that aims to support the achievement of development results. Meanwhile RBM can serve various purpose. Section 2.1 summarises if and how the reviewed organisations have defined a goal and purpose(s) for RBM. During implementation, RBM either supports the purpose (section 2.2) or can face challenges or lead to unintended consequences that are contrary to its purpose (section 2.3).

The third part of the report explores ways forward, taking into account the changing development cooperation context. Following an analysis of the solutions and recommendations made in the reviewed evaluations (section 3.2), it presents the new theories and initiatives that are being developed and discusses whether these approaches could be considered as different from, or complementary to, classical RBM approaches (section 3.3).

\subsubsection{Documents reviewed}

The review draws primarily on findings from evaluations and reviews conducted on whole or parts of the RBM systems of development co-operation providers during the past four years (2015-2018). Criteria and process for selecting documents have led to the review of three main types of documents (Box 1):

i. Evaluations and reviews on RBM performance among providers

ii. Evaluations and reviews on results-based financing mechanisms 
iii. Other evaluations, reviews and papers analysing RBM experiences, including experiences with evaluation utilisation as well as alternative approaches among providers.

\section{Box 1: Criteria and process for selecting the documents}

A choice was made to select recent evaluations (2015-2018). Primarily evaluations and reviews rely on information dating from at least one to two years, therefore, considering earlier material presented the risk of not addressing the interesting questions of adaptation/agility, use of technology or engaging in partnerships. However, to assess progress over time, a number of evaluations conducted prior to 2015 have also been included. The process involved the following steps:

- Identification by the results team of a first series of evaluations previously shared by members.

- Call to the Results Community to share past or projected reviews and evaluations of RBM systems that could inform the synthesis (May 2019). This call was reiterated to members of the ad hoc working group.

- Call to the Evaluation Network at the DAC Network on Development Evaluation meeting on 28 June 2018 for sharing evaluations relevant to the synthesis.

In selecting evaluations and reviews the following criteria were applied: a) deal with challenges and progress in RBM implementation at the provider level; b) provide a broad organisational overview of RBM implementation within the aid provider; and c) be conducted by a third/independent party.

Other documents considered were: a learning synthesis on RBM based on the DAC peer reviews conducted in 2016-17; a synthesis of RBM case studies conducted by the Results team; and findings from the MOPAN assessments conducted in 2015 and 2016.

Annex 1 includes tables listing the documents reviewed in each category, summarising: a) the organisation studied and title of the evaluation; b) the purpose of the study; c) the main method used; and d) whether earlier evaluations or reviews were conducted.

The documents reviewed are different in scope, focus and methodology. Whilst some have analysed the RBM systems as a whole, others have only looked at parts of it. Most of the reviews have a focus on the performance of RBM within development co-operation providers. Therefore, most studies have not examined the influence of RBM systems on recipients and none of them have this as a main focus. Some of the studies have however included field visits which examined how partner countries are affected by the providers' RBM systems and requirements (e.g. SDC, 2017; Norad, 2018a; EU, 2017).

A majority of the reviews have not included the organisations' evaluation function and evaluation systems as part of their analysis. RBM systems are thus typically seen as including continuous planning and monitoring of the organisations' corporate, country strategy and project activities. However, since evaluations and the evaluation function are important for RBM, this paper includes a box on evaluation quality and use (Box 3), based on four recent evaluations on the topic (USAID, 2016; Norad 2018b; GAO, 2017; Finland, 2018a).

As an attempt to provide an overview over time, the material has been compared with a few similar evaluations from the past (noted in table 1 of annex 1) as well as an analysis of evaluations and reviews examined as part of a similar review undertaken in 2011 (Vähämäki et al., 2011). A limitation in this study is that it has not been possible to conduct a broader review in respect to how RBM systems evolve over time and as a response to RBM evaluations. An example is however given of how the Ministry of Foreign Affairs (MFA) of Finland has responded to the RBM evaluations (Box 2).

In addition to the document review, interviews and in-depth discussions at different stages of the drafting process have been conducted with some members of the reference group that accompanied the project. 


\section{State of play - Findings from the reviewed documents}

\subsection{The purpose of results-based management}

What RBM is, how it should apply and its purpose have evolved since 2005. There does not exist today one definition of RBM and its purpose. A recent OECD study comparing development co-operation providers' RBM systems states that "the ultimate purpose of development co-operation is achieving development results (outcomes and tangible change). Development co-operation contributes to development results and resultsbased management supports this effort" (OECD/DAC, 2017:8). If comparing the 2002 OECD/DAC definition with the latter, one can see that the ultimate purpose of RBM has been clarified and connected with the overall goal of development co-operation.

In a recent study, the OECD assigned four main purpose for results information (OECD, 2016):

- accountability

- communication

- direction/decision-making

- learning.

Accountability and communication are important to gain legitimacy and credibility, both internally and externally, by actors such as domestic stakeholders and development partners. Direction and learning support the organisation's performance in achieving development results, with results information used for policy formulation and strategic decision-making; quality assurance; portfolio, thematic, programme and/or project cycle management.

RBM applies at three levels in development co-operation: corporate level, country/thematic programmes and/or at individual project level. At all levels, results frameworks or a basic results chain link inputs to activities, outputs and ultimately outcomes and impact. The OECD has distinguished between three tiers to which results information can contribute: development results (tier 1); development co-operation results (tier 2); and performance information (tier 3) (OECD, 2017).

All four RBM purpose are valid at the three levels. However, a common finding in RBM research is that different objectives can come in conflict with each other (Vähämäki, 2017). If organisations have for example not defined what type of results information to collect, they can end up collecting a lot of information in vain while overburdening partner organisations with too many requests. Meanwhile not knowing why, when and who needs results information for decision-making can lead to decision-makers receiving information they cannot use. It is therefore important to know what type of information serves the different purpose and different audiences at the different levels. As noted by the OECD, results-based management approaches benefit from a clear purpose and ambition that is aligned to the agency profile (size, modalities used etc.) and strategy (OECD, 2017).

Table 1 below collates how/if the organisations as well as the evaluation teams have defined an ultimate goal and purpose for RBM: i) have they defined a purpose for RBM? and ii) if several purpose are defined, is a priority given within the different objectives? 


\section{Table 1. Purpose of results-based management ${ }^{2}$}

\begin{tabular}{|c|c|c|}
\hline & Purpose of RBM defined by organisation & Purpose of RBM defined by evaluation team \\
\hline $\begin{array}{l}\text { UN } \\
(\mathrm{UN} \\
2017 \mathrm{~b})\end{array}$ & $\begin{array}{l}\text { Five management pillars for the RBM system: } \\
\text { 1. Strategic management: vision and strategic } \\
\text { framework } \\
\text { 2. Operational management: strategic planning and } \\
\text { resource management } \\
\text { 3. Accountability and learning management } \\
\text { 4. Change management: internal culture of results } \\
\text { 5. Responsibility management: partnerships. }\end{array}$ & $\begin{array}{l}\text { Managing for the achievement of intended organisational } \\
\text { results by integrating a results philosophy and principles } \\
\text { into all aspects of management and, most significantly, by } \\
\text { integrating lessons learned from past performance into } \\
\text { management decision-making. }\end{array}$ \\
\hline $\begin{array}{l}\text { GEF } \\
(\mathrm{GEF}, 2017)\end{array}$ & $\begin{array}{l}\text { Officially: } 2002 \text { OECD definition: "management } \\
\text { strategy focusing on performance and achievement } \\
\text { of outputs, outcomes and impacts" } \\
\text { Also: improve management effectiveness and } \\
\text { accountability by defining realistic expected results, } \\
\text { monitoring progress toward their achievement, } \\
\text { integrating lessons learned into management } \\
\text { decisions and reporting on performance. }\end{array}$ & $\begin{array}{l}\text { A management strategy by which all actors, contributing } \\
\text { directly or indirectly to achieving a set of results, ensure } \\
\text { that their processes, products and services contribute to the } \\
\text { desired results (outputs, outcomes and higher-level goals or } \\
\text { impact) and use information and evidence on actual results } \\
\text { to inform decision making on the design, resourcing and } \\
\text { delivery of programmes and activities as well as for } \\
\text { accountability and reporting. }\end{array}$ \\
\hline $\begin{array}{l}\text { Finland } \\
\text { (Finland, } \\
\text { 2015) }\end{array}$ & $\begin{array}{l}\text { No clear definition of RBM. } \\
\text { According to evaluation: "The MFA has utilised } \\
\text { results-oriented tools since the 1990s. Since 2012, } \\
\text { driven by an earlier RBM evaluation and an explicit } \\
\text { focus on results in its most recent development } \\
\text { policy, a RBM Action Plan has been formulated in } \\
2012 \text { and is being implemented. MFA still lacks a } \\
\text { comprehensive corporate approach to RBM." }\end{array}$ & $\begin{array}{l}\text { A management strategy that focuses on results (as opposed } \\
\text { to budget and activities) to improve decision-making, } \\
\text { learning and accountability. }\end{array}$ \\
\hline $\begin{array}{l}\text { Norad } \\
\text { (Norad, } \\
2018 \mathrm{a})\end{array}$ & $\begin{array}{l}\text { No clear definition of RBM. } \\
\text { According to evaluation: "The only guiding } \\
\text { documentation is the Norwegian Directorate for } \\
\text { Financial Management's definition of RBM. The } \\
\text { administration has not articulated what RBM looks } \\
\text { like for Norwegian development assistance, how it } \\
\text { should operate at different levels, or the value it } \\
\text { brings to achieving development outcomes." }\end{array}$ & $\begin{array}{l}\text { A management strategy that seeks to ensure the effective, } \\
\text { efficient and transparent delivery of development } \\
\text { assistance using results evidence (e.g. partners' results } \\
\text { reporting and evaluations) to inform the allocation of funds } \\
\text { and shape development policy. Done through setting } \\
\text { objectives, measuring achievement, using this information } \\
\text { to analyse, adapt (learning) and report (accountability). }\end{array}$ \\
\hline $\begin{array}{l}\text { World Bank } \\
\text { (WB, 2017) }\end{array}$ & Not stated in evaluation & $\begin{array}{l}\text { A management strategy or approach aligned with } \\
\text { achieving organisational results. M4R refers specifically to } \\
\text { managing for development results. } \\
\text { Two principles: } \\
\text { 1. Developing a robust system for measuring results (for } \\
\text { 2. Inample, a results framework) } \\
\text {. Instituting adaptive management and ongoing learning }\end{array}$ \\
\hline $\begin{array}{l}\text { SDC } \\
(\mathrm{SDC} \\
2017)\end{array}$ & $\begin{array}{l}\text { SDC staff, management and partners are using } \\
\text { results, performance and context assessments for } \\
\text { steering/decision making, learning and } \\
\text { accountability (at all levels) }\end{array}$ & $\begin{array}{l}\text { Purpose: } \\
\text { 1. Management for results: } \\
\text { - Decision-making, } \\
\text { - Management of results information } \\
\text { - Learning } \\
\text { 2. Accountability for results: } \\
\text { - Accountability to domestic partners, } \\
\text { - Accountability by and to partners }\end{array}$ \\
\hline $\begin{array}{l}\text { United } \\
\text { States Dept. } \\
\text { of State } \\
\text { (US, 2015) }\end{array}$ & $\begin{array}{l}\text { Not defined. According to evaluation: "The } \\
\text { management for results framework is an approach } \\
\text { to linking strategic planning, budgeting, managing, } \\
\text { and measuring programs and projects". }\end{array}$ & Not defined \\
\hline
\end{tabular}

${ }^{2}$ This table only refers to how/if a purpose for RBM was defined in the RBM evaluation/review conducted. Providers may however have defined a RBM purpose in other documents.

${ }^{3}$ The SDC RBM purpose description is from SDC (2014:5). 


\begin{tabular}{|c|c|c|}
\hline & Purpose of RBM defined by organisation & Purpose of RBM defined by evaluation team \\
\hline $\begin{array}{l}\text { CGIAR } \\
\text { (CGIAR, } \\
2017)\end{array}$ & Not defined & $\begin{array}{l}\text { Ten principles of RBM: Results focus, consistent } \\
\text { leadership, commitment to measurement, change in } \\
\text { organisational culture, systems thinking, investment in } \\
\text { learning, practical understanding of accountability, wide } \\
\text { participation, integration of monitoring and evaluation, } \\
\text { investment in information systems. }\end{array}$ \\
\hline
\end{tabular}

The table shows that, from the material reviewed, only the UN, GEF and SDC have formally defined a purpose for RBM in their organisation. This is interesting since without a purpose defining what RBM is expected to contribute to, it ought to be difficult to evaluate RBM implementation in the organisations. Finland, Norad and CGIAR evaluations specifically note that the fact that the organisations have not specified why they are doing RBM has affected the implementation of their RBM reforms. The CGIAR evaluation also notes that this has reduced the learning potential of RBM, created confusion within the organisation about what RBM was meant to do, and undermined the motivation for RBM (CGIAR, 2017).

Among the documents reviewed, the UN has the broadest definition and understanding of RBM. JIU has produced a comprehensive RBM model with a benchmarking framework to define its approach and methodology and to assess stages of RBM development and outcomes. The model includes a strategy for different management functions of RBM, explaining how different purpose should serve different audiences (UN, 2017b).

The UN also has the broadest concept for accountability, 'collective accountability', which is seen as accountability relations at the vertical and horizontal levels, including partner countries. The UN is also the only provider, and the SDC evaluation team the only evaluation team, that recognises that RBM also plays a role for partner countries. This is interesting since the idea of RBM being developed for supporting partner country results was at the core of the MfDR definition. In the Paris Declaration (clause 46) partners and providers jointly commit to "work together in a participatory approach to strengthen country capacities and demand for results-based management".

Finally, the extent to which the purpose definition guided RBM implementation and contributed to improved RBM implementation is unclear. As an example, even though the UN has developed a comprehensive framework and strategy for RBM, the evaluation notes that this has not been mainstreamed within the organisation. A reason for this lies in the externally driven process that UN organisations are subject to, as they need to respond to external constituencies, including bilateral providers, who influence their approach to results management.

To conclude, a number of providers do not communicate clearly the purpose of the RBM system and how it contributes to achieving development results. This makes it more difficult to assess how RBM has worked in practice.

\subsection{Progress made: what has improved and how is results information used?}

In line with findings from seven case studies of RBM by development co-operation providers that the Results team conducted in 2017 (OECD, 2017a), this review confirms that development co-operation providers are at different stages in implementing RBM in their organisations. Even though RBM has been a preferred management approach in most agencies over the past 15-20 years, some agencies are still at a stage of defining what RBM means for them while others have a clear perception of RBM and a well-defined plan under implementation. Still, none of them has reached a stage where RBM is broadly mainstreamed with implications for system-wide operation, partnerships, co-ordination and collaboration.

All organisations which had conducted previous evaluations or reviews of RBM (UN, GEF, Finland, WB and SDC) state that they have made progress over time. As illustrated by the case of Finland, this suggests that conducting RBM evaluations regularly can be beneficial: they can spur action in organisations, contributing to learning on RBM per se and helping to adapt and have a system fit for organisational needs (Box 2). 


\section{Box 2: Learning from RBM evaluations - experience from Finland}

Finland has conducted several evaluations of its RBM approach (Finland, 2011; 2015; and 2018a). It is also currently conducting an evaluation on knowledge management and learning from results (Finland, 2018b). The evaluation conducted in 2011 found that results-based management and reporting were inadequately applied and used. No evidence was found of overall progress towards the increased use of RBM practices. Projects had weak results frameworks, inadequately defined targets at outcome and output levels, indicators were often not measurable and baseline studies were lacking. The evaluation led to several changes (e.g. adoption of a RBM Action Plan 2013-2014, guidance for RBM, introduction of country strategy results frameworks and development of multilateral influencing plans). However, the 2015 evaluation noted that a number of RBM challenges remained.

The 2015 evaluation was more holistic, analysing how the government guidance documents supported RBM and the role of management in supporting the achievement of the related objectives. The Management Response to that evaluation has been crucial for RBM actions taken since then. The Ministry has developed an action plan for 20162018 to implement systematic RBM improvements at project, policy channel and holistic development policy levels. Theories of change have been developed for each priority area, thereby challenging the existing management structure primarily based on financial allocations to specific partnerships. The theories of change have enabled different actors to define a joint vision of Finland's contributions to a priority area. Results are now reported on the vision, a layer above country level, and in an annual synthesis report.

Whilst there still exists several challenges with RBM implementation (e.g. data quality and reliability, workload balance), it seems that the RBM efforts have led to greater awareness in Parliament, with Parliamentarians becoming more interested in a comprehensive analysis of results rather than just the annual activity and financial allocation reports. There is also more appetite to learn about RBM and develop RBM practices within the Ministry.

Source: Finland (2011; 2015; 2018a; 2018b), and interview with MFA Finland.

Main areas of progress relate to: i) RBM procedures and systems; ii) output and short-term outcome data; and iii) results reporting and use of results for domestic accountability. Meanwhile uneven progress is noted on the use of results for decision-making and learning purpose.

\subsubsection{Strengthened RBM procedures and systems}

Development co-operation providers have made progress with establishing procedures and systems for RBM implementation. The Norad evaluation for example states that "a number of the foundational features of RBM are in place in the aid administration" (Norad 2018a:8). These features include some of the technical aspects of RBM such as measuring results, making sure results evidence is reported at the right time, and having systems in place to aggregate different data sets to create a summarised picture of results. The report also notes that progress has been made at the level of grant management and on improving the quality of partner results data, meaning that the availability of data has improved (Norad 2018a).

Similarly, the UN evaluation states that there is now a "significant level of readiness for enhancing the value of results-based management for organisational effectiveness and for the implementation of the 2030 Agenda" (UN 2017b:px). According to the report, most of the UN organisations are at stage four out of five of RBM development - with reference to the stages of development that organisations are going through as they progressively seek to achieve a high-impact results system in mainstreaming all key dimensions of the results approach as defined by the UN. This means that RBM is applied with good coverage across the organisations, continuous learning for refinement of the system and an outcome-focused approach. However, the approach remains predominantly internally-focused and is not fully integrated in all aspects within the organisation. The evaluation therefore concludes that the "added value of results-based management to organisational effectiveness has not been fully realized" (UN 2017b:x). Similarly, the WB evaluation notes that the World Bank Group "has made good progress on building a measurement system, though fundamental measurement issues remain" (WB, 2017:xi).

The evaluation on Finland also notes that important progress has been made towards integrating RBM in planning, implementation and reporting. Comprehensive results-oriented country strategies and multilateral 
plans with results frameworks continue to be developed (Finland, 2015). Meanwhile in SDC the RBM guidelines and instruments on corporate, country and project levels are largely focused and well understood, and they allow for flexibility and contextualisation. The system and instruments in place support a pragmatic and effective results management perspective in virtually all aspects of aid delivery (SDC, 2017). The evaluation on Canada also found that programme evaluations improved in quality when RBM tools were used during planning, also when clear logic models, precise and suitable performance indicators, and monitoring processes were put in place (GAC, 2017).

An overall conclusion drawn from the MOPAN assessments conducted in 2015-16 was that results-based management systems in multilateral organisations are relatively advanced. Most organisations measure results at all three tiers (performance information, country results and development results). However, only a few organisations (World Bank, UNAIDS and to some extent Gavi) have established a logical link between the tiers. Whilst RBM systems have proven supportive of communication and accountability, challenges remain due to poor data quality, time-lag in data, and gaps between organisational objectives and indicators used to measure programme impact.

The elements above show that RBM systems, guidelines and tools are now in place in many development cooperation agencies. Moreover, some providers are starting to incorporate the Sustainable Development Goals (SDGs) into their agency-wide results frameworks. For example, the Netherlands and SDC have mapped tier two indicators to the SDGs at goal level, and around half of New Zealand's tier one indicators map directly to relevant SDG indicators (OECD, 2017a). While there is still a long way to go, these are key steps towards using the SDGs as a shared results framework.

\subsubsection{Progress in tracking outputs and short-term outcomes}

The GEF evaluation mentions that progress has been made "in terms of tracking of results, while expected outputs and outcomes of supported activities are clearly specified" (GEF, 2017:5). DAC peer reviews also show that the twelve DAC members that were subject to a peer review in 2016-17 have all made efforts to improve results-based management and that, overall, members are progressively moving from defining and measuring outputs at project level towards defining and measuring outcomes (OECD, 2017c). However, in many cases, the focus remains mostly on outputs and short-term outcomes. For instance the WB evaluation notes a "good focus on the outputs of World Bank Group operations" (WB, 2017:7). The OECD report echoes this finding, stating that information about development co-operation results (outputs and immediate outcomes) and performance information (inputs) are often favoured over information about development change or long-term outcomes (OECD, 2017a). ${ }^{4}$

While some providers take a contribution approach, an increasing number claim direct attribution. As noted by the OECD, they use standard indicator sets in their corporate results frameworks to aggregate project-level data and report on agency-wide achievements. This requires results information that is easy to aggregate, which is the case with output data. Some providers also tend to measure project effectiveness and quality by aggregating project-level ratings. These ratings assess the extent to which output and outcome results have been achieved or are on track to be achieved at project level (OECD, 2017a).

The increased focus on outputs can also be seen as a consequence of the more fragmented development landscape that involves a greater number of actors, channels and instruments. Many DAC members tend to diversify their development co-operation modalities, reducing government-to-government co-operation and adopting more "project-based" approaches involving non-governmental channels, private sector instruments and multilateral organisations (OECD, 2017a).

This emphasis on tracking outputs happens at the expense of focusing on longer-term outcomes, and therefore leads to a first unintended consequence of RBM systems: measure fixation (Box 3).

\footnotetext{
${ }^{4}$ The report also notes that policy-level decisions among providers are often based on performance information only.
} 


\section{Box 3: Unintended consequence - 1. Measure fixation: focus on what can be measured easily}

Measure fixation happens when some measures are emphasised at the expense of others, such as: quantitative aspects at the expense of qualitative aspects in performance measurement schemes; and short-term targets (inputs/outputs) at the expense of long-term objectives (outcomes/impact).

The fact that providers are increasingly using standard indicator sets can occur at the expense of improved knowledge, measurement and reporting on outcomes and long-term objectives. In the case of Norway, RBM requirements have pushed partners to use quantitative indicators which can be aggregated across the portfolio of grant-supported projects. This has led to a focus "on what can be easily measured rather than what is important" (Norad, 2018a:45). Overall a growing body of literature critiques the use of standard indicator sets to aggregate project-level results information. Such efforts have contributed to a range of unintended consequences, in terms of reporting burden, poor data quality, perverse incentives (related to both reporting and programming), inability to capture the totality of results achieved, and a loss of focus on learning.

Multilateral organisations also tend to focus more on outputs, as noted by the UN and GEF evaluations. This undermines efforts to measure actual impact and, in the case of the GEF, to track the environmental trends relevant to its work. The OECD notes that the increased attention on output rather than outcome information results in providers being unable to explain how they contribute to changes in the countries where they work as well as how they contribute to overall global goals such as the SDGs. Moreover, "this has undermined attempts to foster country ownership of results information and the ability to use it for insights, learning and ultimately to understand how to achieve outcomes" (OECD, 2017a:9).

Measure fixation can also lead to systematic collection of baseline data, with a mixed impact on partners. For instance, all partners of the Norwegian administration need to have results frameworks with baseline data and targets. While this has generated useful insights and provided civil society organisations (CSOs) with a much better picture of change, it has caused a tension with local partners since they were being asked to set baseline information before funding had been guaranteed (Norad, 2018a:46).

In summary, RBM tends to in practice prioritise what can be measured easily, favouring quantitative data over qualitative evidence (even though the latter can better reflect the reality of programme implementation) and short term targets over long-term outcomes.

Source: OECD, 2017a; UN, 2017b; Norad, 2018a; GEF, 2017; Holzapfel, 2016; Shutt, 2016; ICAI, 2015; World Bank, 2016

\subsubsection{Better use of results information for reporting and domestic accountability}

Most of the evaluations report progress on results reporting. Some see this progress as the most important achievement of RBM. The UN evaluation for example states that: "the most significant contribution of results-based management for United Nations system organisations is in providing a structure for reporting evidence of results to their respective governance bodies" (UN, 2017b:xi).

Many evaluations note that accountability has been the principal driver of RBM. The Norad evaluation for example clearly states that the main focus of RBM within the administration is to gather and use results evidence to demonstrate what partners have achieved with Norwegian tax payers' money and to report this to senior management, parliament and the public (Norad, 2018a:8). Furthermore, the evaluation notes a positive effect in that RBM has contributed to a greater transparency in the use of Norwegian development assistance and improved public understanding and possibly trust in development co-operation.

Similarly, the GEF evaluation notes that the RBM system facilitates reporting on progress in the use of GEF resources, the efficiency and effectiveness of its activities and processes, and its environmental results. The annual portfolio monitoring report and the Corporate Scorecard system provide useful information to the governance bodies, in particular Council and management (GEF, 2017). 
The SDC evaluation notes that while there is a clear perception within the organisation that results reporting aims to satisfy the information needs of domestic constituencies, perceptions vary considerably on how to best meet their needs. Domestic demand, and the type of results information that is requested, is seen as unclear and changing over time. The evaluation however points out that building trust through conveying the message that the agency has a sophisticated system in place could be a centrepiece in future communication for accountability purposes (SDC, 2017).

\subsubsection{Uneven progress on use of results for decision-making and learning}

Some evaluations (UN, 2017b; Norad, 2018a; SDC, 2017) mention progress in the use of results for direction and learning. The Norad evaluation notes that the administration's RBM requirements have spurred partners to invest in and strengthen their own systems. It also states that there are instances where results data was used to inform decisions related to resource allocations between countries and to improve partners' understanding of change, thereby bringing added value and plausibly leading to better development outcomes (Norad, 2018a:9). Evidence also shows that evaluations are used for programming and learning (Box 4).

\section{Box 4: Evaluations are used for programming and learning}

The two evaluations conducted on evaluation utilisation arrive at relatively positive conclusions (USAID, 2016; Norad 2018b). The USAID evaluation, for example, argues that in general there is a high rate of evaluation use in USAID: evaluations are being used to improve programming in ways that contribute to better development outcomes. Moreover, learning from these evaluations is happening in the form of evidence-based decision-making and an increased understanding of the context in which USAID operates. The evaluation concludes that evaluations are used both in project design and implementation phases to revise USAID activities. Similarly, the Norad evaluation found that reviews were generally considered to be timely and to present relevant and realistic recommendations. Timeliness was linked to the eventual use of reviews and whether they influenced decisions.

Source: USAID, 2016; Norad, 2018 a

However, this progress has been uneven within and across organisations. The Norad evaluation found little evidence that results were systematically used to inform decisions on either what or whom to fund or in the design of grant schemes at the agency level. It concluded that "other factors such as political priorities or the fact that an organisation was a long-term partner seemed to have the most significant bearing on the final allocation decision" (Norad 2018a:8). Meanwhile the UN evaluation noted that use has been exercised principally in managing the portfolio of programmes and projects, minimally in shifting resources, and not in areas such as human resource management (UN, 2017b).

Both the SDC and GEF evaluations also found an uneven use of results information for direction. The SDC evaluation found progress in use of results data for analysis or planning in some geographical departments of the organisation, whereas other geographical departments have not used them (SDC, 2017). Similarly, the GEF evaluation notes that the role of RBM in evidence-based decision making has not received as much attention as accountability to the Council (GEF, 2017). This statement echoes findings from other evaluations, i.e. that use of results for decision-making had not been the primary focus of RBM efforts. The United States Department of State evaluation notes that there is little evidence that results data has been used for decisionmaking or learning (US, 2015). The evaluation on Finland also states that much of the information gathered by individual units is neither transmitted nor used by management (Finland, 2015).

This uneven progress in the use of results for decision making and learning illustrates a second unintended consequence - suboptimisation - resulting from the fact that accountability drives to a large extent the results agenda (Box 5). 


\section{Box 5: Unintended consequence - 2. Suboptimisation}

Suboptimisation happens when an organisation focuses on improving one component of a system without considering the effects changes made have on the other parts of the system. It can for example imply that: i) one part of the organisation becomes more effective at the expense of pursuing effectiveness of the whole organisation; and/or ii) one RBM purpose is pursued at the expense of the others (Smith, 1995; Thiel and Leeuw, 2002).

Several evaluations note that RBM reforms have led to a skewed focus in favour of accountability and reporting, at the expense of learning and decision-making. RBM is perceived as a compliance exercise designed to satisfy external reporting requirements and domestic accountability without balancing the two main purposes of RBM - learning and accountability. It has also altered partners' RBM systems: they tend to generate data for reporting rather than for improvement and learning: in some cases, partners collect data because it is a reporting requirement, without using it to inform internal decisions. The OECD also notes that the increased focus on input and output data for accountability purposes has undermined attempts to foster country ownership of results information and the ability to use it for insights, learning and ultimately to understand how to achieve outcomes. As a result, "in many cases development co-operation results have become detached (and de-contextualised) from development results" (OECD, 2017a:9).

Suboptimisation questions the role and responsibility of leadership. The UN evaluation for instance mentions that the focus on reporting and accountability has led to "a leadership that is responsive but not responsible" (UN, 2017b:viii). While leadership has focused on responding to the accountability needs of the member states, "it has not exercised responsibility for meeting the demands for managing for achieving results, which includes a focus on making the changes and adjustments necessary to ensure success and sustainability" (UN, 2017b:ix). Similarly, the United States Department of State evaluation notes that the Department leadership does not consistently engage in RBM processes or use RBM products (e.g. performance reports). Inconsistent leadership engagement at each level within the organisation is a barrier that continues to hinder the adoption of the RBM framework.

In the case of multilateral organisations, the funding structure can be a factor of suboptimal implementation. Funding providers have different visions, objectives and operating principles as well as various motivations for RBM. In the case of CGIAR, some funders require performance contracts to provide standardised measurements and annual performance reviews, whereas others emphasise learning. Similarly, the UN evaluation notes that the effective use of results evidence is hindered by the high pressure to respond "to the copious amount of information on results for reporting to the parliaments of donor countries and the public" (UN 2017b:xi). Another factor of suboptimisation might be the perceived need for consistency in measurements for comparisons over time or over contexts (Kusek and Rist, 2004).

Sources: US, 2015; SDC, 2017; UN, 2017b; Norad, 2018a\&b; CGIAR, 2017

On the learning aspect, the WB evaluation states that "projects are generally weak in their attempts to learn empirically about the validity of the change theory underpinning the project or programme, and about other factors that might affect outcomes". It also noted that staff do not get incentives for candid self-evaluation that would lead to learning (WB, 2017). Similarly in Finland, learning from results "happens in an ad hoc fashion rather than in a regular and systematic process" (Finland, 2015:22). The OECD also notes in its analysis of the 2016-17 DAC peer reviews that five members mentioned challenges with building a culture of learning from results, and only two DAC members use results data to inform budgetary decisions (OECD, 2017c).

Meanwhile the MOPAN assessments show that many of the multilateral organisations have set up advanced systems for learning and decision-making. The AfDB for example has set up a database for learning from evaluation findings, and UNDP and the World Bank continuously share learning studies. However, as is the case for other providers, the multilateral organisations face difficulties with using results information for learning and decision-making. Learning actually takes place through informal ways, such as peer-to-peer (OCHA, UNAIDS, WB). The UNAIDS' assessment for example states that the organisation does incorporate lessons in its operations but, in the absence of a formal system for learning uptakes, there is no evidence proving whether and how this happens. 
To conclude, the fact that RBM systems are not systematically used for decision making and learning echoes a finding from seven case studies conducted by the OECD in 2017, which showed that providers tend to adopt a "dual track" system which separates domestic accountability and communication at corporate level, from learning and adaptive management at project and programme level (OECD, 2017a).

\subsection{Challenges}

In addition to achieving a better balance in using results information, a number of challenges and difficulties remain. They include a weak results culture and lack of guidance on RBM; structural and system issues; measurement and method issues; and challenges related to ownership and harmonisation. As in the case of measure fixation (Box 3) and suboptimisation (Box 5), providers are also faced with further unintended consequences when implementing RBM reforms (counterproductive implementation).

\subsubsection{Lack of guidance and weak results culture}

In spite of being often considered as a prerequisite for RBM, the establishment of a results culture supported by appropriate staff guidance and incentives remains a challenge in provider agencies. More emphasis needs to be put on the importance of senior management pioneering the use of results data in their day-to-day work.

Several evaluations discuss the lack of a results culture within the organisation (Finland, 2015; WB, 2017; OECD, 2017a; Norad, 2018a). The Finnish evaluation, for example, argues that "the MFA has not yet been able to create an organisational environment conducive to RBM. The organisational culture remains largely risk-averse and prioritises diligent compliance and accountability over careful experimentation and learning" (Finland, 2015:18). Similarly, the Norad evaluation notes that a results and learning culture is not yet in place; staff do not systematically seek out and learn from results data and evaluations. The CGIAR evaluation also notes that the lack of a shared conceptual understanding of RBM reduces its learning potential (CGIAR, 2017).

Some evaluations argue that the lack of a results culture is due to staff attitudes lacking a results-oriented 'mind-set'. The UN evaluation suggests that the UN system faces challenges in addressing behavioural aspects that are important for transformative change and for applying a human-centred paradigm (UN 2017b:ix).

Other evaluations link the lack of a results culture to management challenges, leading to a lack of guidance or understanding within the organisation on how to implement RBM in practice. This finding reflects the fact that few providers communicate clearly the purpose of RBM (section 2.1). The Finland evaluation notes that whilst development polices and strategies convincingly convey the values and overall guiding principles of Finnish development policy, they "provide very little guidance with relevance for RBM" (Finland, 2015:17). Also, the Norad evaluation states that "commitments to being 'results orientated' and ensuring 'funds deliver results' are consistently found in government documents, but there is no detail on what this should look like in practice" (Norad, 2018a:7).

Lack of appropriate incentives are also mentioned. The WB evaluation found progress in building a culture of 'evidence-based adaptive management and learning', but argues that it still needs a stronger, more systematic and holistic push (WB, 2017). It notes for example that disbursements and lending have priority over outcomes in staff incentives (WB, 2017). The OECD also notes that staff are often incentivised more towards design and disbursement than RBM of projects during implementation and at completion (OECD, 2017a). The United States Department of State evaluation also argues that a comprehensive human resource management strategy is not in place to ensure appropriate staff incentives for RBM implementation and use (US, 2015). The RBM training guidance of the Office of United States Foreign Assistance predominately focuses on the implementation of individual processes or products rather than of the entire RBM framework. It does not sufficiently reinforce linkages between RBM processes and lacks guidance in helping stakeholders to incorporate RBM processes in their regular responsibilities (US, 2015). 


\subsubsection{Structural and systems issues}

Structural and systems issues, i.e. issues dealing with inconsistencies in policy and budget, inconsistencies between planning and reporting as well as organisational responsibility for RBM processes or systems and capacity constraints are commonly raised challenges.

Both the Norad and Finland evaluations note a disconnect between policies and budget. The Norad evaluation argues that while the goals and objectives are often specified at a broad policy level in the annual budget proposal, these are not operationalised in either the Norad allocation letters or in the funding allocations to departments and sections within the MFA. This makes it very difficult for the administration to practice RBM at a strategic level (Norad, 2018a). Similarly, the Finnish evaluation states that "policy formulation and budgeting processes at the MFA remain largely separate and budget planning itself is not results-driven" (Finland, 2015:7). This poses inherent problems for RBM since it is difficult to commit to results without knowing what resources will be available. ${ }^{5}$ The evaluation concludes that this also constitutes a problem for Parliament and the society at large since they remain without an adequate understanding of whether originally intended objectives have been reached and whether Finnish development co-operation represents a good social investment (Finland, 2015).

On a similar note, both the GEF and United States Department of State evaluations discuss challenges with integrating planning and reporting. The GEF evaluation notes that the long duration of projects constrains reporting on actual results on the ground against targets and use of this information in future work. The United States Department of State evaluation also mentions this timing challenge and adds that the strategic planning process is constrained by inconsistent or ambiguous high-level policy guidance and competing country-level planning models. This complicates adoption of RBM frameworks and use of strategic plans by stakeholders, thereby hindering United States Department of State's ability to effectively communicate with stakeholders (US, 2015).

The UN evaluation notes a number of system challenges such as: i) engaging with multiple actors, which makes the UN system subject to a variety of external governance frameworks, limits its global leadership role and, at times, increases its exposure to various types of risks; ii) the financing system, which creates competition and reinforces functional silos, thus limiting joint and integrated ways of working; and iii) the integration of results principles into the human resources management system (UN, 2017b). Consistent and full mainstreaming of RBM is also constrained by the externally-driven process that UN organisations are subject to, as they need to respond to external constituencies who influence their approach to results management. This externally driven process leads to "favouring a reactive and fragmented approach, rather than a comprehensive and integrated mainstreaming of results-based management" (UN, 2017b:28). The evaluation also mentions that information for personnel performance management is constrained by "the paternalistic approach of the United Nations system, as well as the preferences of and political interference by members of the Executive Board" (UN 2017b:x).

Meanwhile, the evaluation of SDC finds that the constraints relate to a lack of clear management structure with lines of responsibility established for the different processes (SDC 2017:iv).

Finally, several reports discuss the challenge of capacity constraints. These relate to:

i. matching staff capacity to the different RBM requirements (WB, 2017; SDC, 2017; UN, 2017b);

ii. strengthening staff competencies in measurement, analysis and evaluation, e.g. in methods for evaluation in complex and unpredictable contexts (WB, 2017; SDC, 2017; UN, 2017b);

iii. dealing with limited capacities for results and data in partner countries (UN, 2017b).

\footnotetext{
${ }^{5}$ The evaluation raises several other organisational system challenges related to RBM implementation: i) annual reporting is not systematic and seldom done with reference to original targets; ii) no discussion takes place on why objectives have not been met; and iii) there is no comprehensive corporate level reporting that covers entire aid channels or aid instruments, or policy coherence work.
} 
A common argument is that RBM requires significant resources and that insufficient number of staff have been devoted to RBM activities. The United States Department of State evaluation, for example, noted that responsibilities for managing resources have increased, but corresponding policies, guidance and staff resources have not expanded (US, 2015). In addition, RBM requirements tend to increase over time such as the need to access and analyse disaggregated data.

However, the topic of cost/effectiveness of RBM is not discussed to a large extent in the evaluations. The SDC evaluation however questioned the cost-efficiency of the Effectiveness reports produced by SDC to contribute to both organisational learning and public accountability. The reports cost between CHF 250,000 and 400,000 (USD 260,000 to 410,000) per report, which is not found to be a cost-efficient investment nor to support the two purposes (SDC, 2017:9).

These system issues lead to a third unintended consequence, in the form of counterproductive implementation involving huge transaction costs and affecting staff motivation and creativity (Box 6).

\section{Box 6: Unintended consequence - 3. Counterproductive implementation}

Counterproductive implementation often occurs when performance measurement schemes become overly bureaucratic and rigid. This carries the risk of:

Increased transaction costs and administrative burden, with staff spending increasing amounts of time collecting data and monitoring their activities at the expense of managing the programme and engaging with partners. This is reflected in a number of evaluations. The UN evaluation for example notes that "an excessive use of professional capacities of staff are used to report on results". The GEF evaluation adds that although the administrative burden has decreased since the previous evaluation (2013), the organisation is "still tracking too much information", which is complex and burdensome for the organisation (GEF, 2017:10). The 2018 Norad evaluation also argues that the administrative requirements have led to significant amounts of time required to collect results information. Still, the development co-operation administration has rarely thought through exactly why it needs the requested data, other than to monitor what partners are doing. Meanwhile partners are in some cases reporting data because they think the provider needs it, without seeing a value for their own purposes. Moreover, a particular challenge is responding to ad hoc requests that are directed at partners in response to media or parliamentary questions. Since these cannot be predicted they often require extensive consultation with national level staff to answer. All of this has led to partners over-reporting and increasing transaction costs. The evaluation argues that partners "report more than necessary to cover all eventualities" (Norad, 2018a:45). Over-reporting and overdoing what is requested is a common strategy in situations of uncertainty (Vähämäki, 2017). Organisations track more information than necessary to safeguard eventual requests from external constituencies.

Reduced motivation, innovation and creativity among staff as well as reduced risk taking. Burdensome procedures can have damaging effects on staff relationships, motivation and performance. They also tend to reduce trust and workers' autonomy (Diefenbach, 2009; Smith, 1995; Honig, 2018). As an example, according to Shutt, DFID staff operating at country level have little decision-making power, and standard indicators have a negative effect on contextually relevant programming, leading to compliance rather than risk taking. Staff were allegedly so disempowered that they were disinclined to challenge the results culture (Shutt, 2016). The latter effect has also been observed at Sida, where RBM reforms first led to staff opposition but then to compliance and silence, because of fear of consequences (Vähämäki, 2017). The SDC evaluation notes that staff are less likely to report on failures, and the AFDB evaluation reports that staff focus on control rather than on proactive risk management (AFDB, 2018). This can prevent honest and creative discussions in project implementation, and likely affects many development cooperation agencies, including multilateral organisations: the UN evaluation points out that staff are concerned with being seen as unsuccessful when outcomes are not reached, and that RBM "has not engendered trust, creativity, and innovation as one would expect of the philosophy for managing for achieving results" (UN 2017b:vi). It has rather led to the development of organisations that operate with external locus of control, as they seek to address the power dynamics governing their respective organisations.

The Norad evaluation adds that relations with CSOs have worsened, as they feel that the way RBM is being promoted by the administration risks shifting the nature of the relationship towards a more transactional, rather than partnerbased, relationship (Norad 2018a).

Source: EU, 2017; GEF, 2017; Norad, 2018a; UN, 2018b; SDC, 2017 


\subsubsection{Measurement and method issues}

All evaluations note challenges with collecting reliable results data and information, as follows:

i. Inadequate tracking tools and measurement formats; this includes gaps in submission of tracking tools at midterm and project completion and inconsistency in measurement formats (GEF, 2017); organisation's measurement systems that do not support the longer-term data collection required (WB, 2017); inadequate intervention information system(s) for monitoring and reporting results across the MFA aid channels (Finland, 2015); inconsistent use of logical frameworks (AFDB, 2018).

ii. Poor data quality due to generally weak client data systems; weaknesses in measurement of outcomes and long-term impacts (WB, 2017); the absence of impact indicators (GEF, 2017); inconsistencies between quantitative reporting and original targets (Finland, 2015); poor credibility of ratings and inadequate quality of indicators, baseline and data (AFDB, 2018).

Evaluations also note that data is often of limited use, either for evidence-based management (WB, 2017); ranking and prioritising results (EU, 2017); attribution and aggregation (UN, 2017b); or for systematic reporting on performance and results (Finland, 2015, GEF, 2017).

Challenges with measurement can form a vicious cycle. At the design phase, objectives often remain vague, a theory of change articulating how results are linked to goals is not developed ${ }^{6}$, and baselines are rarely specified. Data is of poor quality and limited value during implementation. Results frameworks often measure processes rather than outcomes. Staff tend to focus on outputs that are within their control and achievable. They can also be cautious of the consequences of not achieving outcomes, therefore favouring reporting positive outcomes or becoming excessively risk averse (WB, 2017).

The EU evaluation suggests that these challenges become even more difficult in multi-stakeholder programmes: "with a dozen or more donors involved, unless results are ranked and prioritised, a joint results framework tends to be nothing more than a compilation (or 'shopping list') of participating donor objectives drawn from the country results framework" (EU, 2017). The UN evaluation confirms that there is often a "confusion over the application of the concepts of outputs and outcomes and accountability for what one can control, compared with responsibility to ensure outcome achievement through coordination, collaboration, co-management, partnership, advocacy, and building on the comparative value of the United Nations system" (UN, 2017b).

\subsubsection{Ownership and harmonisation}

As part of the Busan Partnership Agreement (2011) development co-operation providers have committed to using partner countries' data and systems to measure the contribution of their interventions to the outcomes and change that these countries seek to achieve. In addition to supporting partner countries' capacities in managing national results frameworks and associated statistical systems, they have agreed to minimise the use of parallel frameworks. However, the overall review shows that focus on ownership has been limited, including in building country systems and using national data, and that harmonisation efforts among providers have proven to be challenging.

Only three of the reports (OECD, 2017a; SDC, 2017 and UN 2018b) review the extent to which these development effectiveness commitments are followed. The OECD draws a mixed picture: "providers intend to honour this commitment, but evidence suggests this is not being realised". Results information generated by the partner country is seldom used in corporate results frameworks. At partner country level, while most providers include country-level data in their country strategies and results frameworks, limited use is made of country results information and monitoring systems. "In most of the case studies, country level results-

\footnotetext{
${ }^{6}$ The evaluation states that "despite instituting results-based country assistance strategies, the results frameworks in country strategies had weak links between designed interventions and outcomes and weak indicators to track outcomes" (WB, 2017:8).
} 
based management is viewed as the most challenging aspect of the results approach. In particular, the extent to which partners are actively consulted during development and ongoing monitoring and review of provider specific country-level results frameworks appears to be limited (...). Accountability requirements, proliferation of additional frameworks at country level and greater use of project modalities all contribute to a reduced focus on country results" (OECD, 2017a). The SDC evaluation states that "SDC can do more to align with the results management principles of the development effectiveness agenda" (SDC, 2017:iv).

The UN evaluation brings up challenges regarding 'collective accountability,' which means accountability both at vertical and horizontal levels across the United Nations system and with partner countries. The evaluation argues that collective accountability around shared outcomes across organisations is difficult to enforce since its success rests on a set of conditions for collective impact, including: a common agenda; shared measurement; mutually reinforcing activities; continuous communication; and backbone support. Collective accountability also depends on "a system that values trust and integrity, and a culture of results that values innovation, measured risk-taking, an internal locus of control and a reasonable amount of selfaccountability" (UN 2017b:65). The evaluation suggests that there is a need to conceptualise a coherent framework for collective accountability across United Nations system organisations with common, integrated criteria for success.

The WB evaluation discusses whether the agency supports partners' RBM systems. Although the Bank has various instruments and approaches to address partners' capacity to manage for results, it focuses only to a small extent on helping them to strengthen capacity for their own use of evidence for adaptive management and learning (WB, 2017). The evaluation suggests that while the effectiveness and results of these efforts have not yet been assessed, a strategic approach to strengthen partners' capacity, based on systematic diagnostics, is needed (WB, 2017).

EU joint programming aims to promote harmonisation through the joint planning of development cooperation by the EU members working in a partner country. The EU evaluation notes that joint results frameworks typically do not have a specific institutional home and thus tend to suffer from the lack of a champion and unclear mandate as to whom should facilitate their use. The ongoing task of co-ordinating joint results frameworks is seldom recognised by EU delegations and in many cases not supported by external technical assistance, thereby threatening institutional memory. Moreover, the evaluation found that in some cases, joint results frameworks have been treated simply as administrative exercises, adopting the high-level indicators of partner governments regardless of how well they fit with the intended joint programme results (EU, 2017).

To conclude this review of the progress and challenges faced by providers in managing for results, it is interesting to note that earlier reviews of RBM systems were less positive about progress made, but found many of the same challenges (Vähämäki et al. 2011; Mayne, 2007). In particular:

i. More evaluations in the current study note progress with RBM implementation. Providers are increasingly aware of why they are doing RBM, and formalities have improved;

ii. The challenges are more or less the same; they relate to leadership, measurement, building a results culture and staff motivation for RBM;

iii. A larger number of evaluations note that there are unintended consequences of RBM. In 2011, the unintended consequences were often discussed as risks of RBM; today, some of these risks are noted as actual effects of RBM reforms.

Finally, even though some evidence points to a positive correlation between the quality of the monitoring and evaluation system at project level and ratings on project outcomes (Raimondo, 2016), the potential contribution of RBM to development results, and the extent to which RBM actually influences system-wide operations of providers, could be explored further (see section 3.1$)^{7}$

\footnotetext{
${ }^{7}$ Only three evaluations discuss whether RBM supports development results (SDC, 20177; Norad, 2018a; WB, 2017).
} 


\section{Ways forward}

The evaluations and reviews provide recommendations or suggestions to address the challenges of RBM implementation that are described above. Meanwhile the changing context for development co-operation influences management methods, leading to introducing 'new', or 'alternative' approaches. The section starts with describing how the changing context impacts on RBM approaches, then describes the solutions suggested in the evaluations and reviews, and ends with broadening the approach to explore the new theories and initiatives that are being developed and implemented.

\subsection{A changing development co-operation context}

The development co-operation landscape is being shaped by Agenda 2030 and its main characteristics, which impact results management in different ways as described below:

1. Agenda 2030 adopted in 2015 is universal and covers not only poverty and development, but inequality and sustainable development. The SDGs, with their 17 goals, 169 SDG targets and 232 indicators, represent an opportunity as a common results platform geared towards outcomes and change, providing a basis for harmonisation and dialogue at country level (OECD, 2017a). However, a commonly raised risk is that the breadth and number of SDG goals and targets hamper international assessment of progress, with each country picking the number and range of indicators that best suits their need.

2. Agenda 2030 and the SDGs require, more than ever, data to demonstrate progress towards the agreed goals. Moreover, implementing the leave no-one behind pledge requires accessing disaggregated data. This is both an opportunity and a challenge for RBM implementation. A vast increase in the volume of digital data can potentially enhance the evidence base for development policy and programming, and ultimately support development impact on the ground (OECD, 2018a). However, the "data revolution" basic data in partner countries, and weak incentives and capacity to fill these gaps.

3. Agenda 2030 and the leave no-one behind pledge put increased pressure on providers to work in fragile contexts. From an RBM perspective, it is generally harder to achieve and demonstrate development results in fragile contexts, since the external environment is unpredictable and institutions are unstable. This has brought about new methods such as adaptive management in which managing uncertainty and complexity are emphasised (ODI, 2017b).

4. Agenda 2030 requires a substantial increase in resource mobilisation to achieve intented results. New actors such as the private sector are considered as increasingly important players for its achievement. More than 50 per cent of the financing needed to achieve the SDGs could be mobilised through the private sector (OECD, 2018b). However, challenges lie in the fact that the SDGs do not yet appear as a driving factor for many private sector actors and the amount of private finance actually mobilised are below expectations. There is also limited evidence of the outcomes of partnerships engaging the private sector, and many projects involving private sector partners have weak monitoring systems unable to produce the information required (OECD, 2018b). More broadly, Agenda 2030 calls for working in partnerships, and measuring results of partnerships involving multiple actors with different agendas can be difficult.

5. Official Development Assistance has shrunk in comparison to other resources such as private financial flows (OECD, 2017b). Many providers emphasise, alongside altruism or solidarity, other motivations, such as political influence, commercial opportunities and security considerations. Meanwhile a number of new providers, particularly South-South co-operation providers, stress the

\footnotetext{
${ }^{8}$ The data revolution is commonly described as a vast increase of digital data that has resulted in the phenomenon known as "big data", characterised by the four "V's" of volume, velocity, veracity and variety (OECD, 2018b).
} 
'mutual benefit' dimension of their co-operation, and develop alternative approaches to assess their results.

The elements above suggest that the pressure for demonstrating results will remain. An increasing interest in how to best manage, achieve and demonstrate how development co-operation interventions contribute to sustainable development results is to be expected.

\subsection{Suggested solutions to the challenges and unintended consequences}

As shown in table 2 below, the most common suggested solution to address challenges faced in implementing RBM is simply to do more or better, e.g. improve leadership and management and/or increase guidance, training and/or measurements. There is therefore a perception that the solution to challenges and unintended consequences of RBM is to maintain, but improve, the current approach so that the real benefits of RBM can arise. The 2017 UN evaluation, for example, states that "results-based management is relevant and has value when implemented correctly, in an intellectually honest manner, and managed on the basis of lessons learned" (UN, 2017b:ix). Reaching the ultimate stage 5 in the benchmarking framework would provide "the real added value of results-based management with a focus on managing for outcomes, applying systems operation, renewal of the organization via evaluation, and applying collective accountability" (UN, 2017b:iv). This would be a stage where theory is fully aligned with practice.

A number of evaluations stress the importance of continuously balancing and following up effects of RBM implementation to improve practice. The Finnish evaluation for example recommends a realistic understanding of the effort needed to introduce RBM, recognising that the required cultural and procedural changes are often underestimated, and a balance between the benefits and risks for accountability and learning when determining the number and type of indicators (Finland, 2015:22). In the same manner, the OECD recommends that providers be realistic about aggregation and attribution, focusing more on the contribution of development co-operation (OECD, 2017:5).

However, reaching a stage of full institutionalisation of RBM into organisational practice, with managing for results 'taken for granted' by actors and results becoming the driving factor, seems unrealistic. ${ }^{9}$ Other political, structural and systemic factors are often at play in steering organisations. Research findings show that results and results-based management direct organisational action only to a minor extent (Jacobsson et al, 2015), and this synthesis confirms that providers seldom use results for decision-making. Budget allocations for instance are highly influenced by political processes, including international commitments and a pressure to disburse. Moreover, practice is almost always messy and organisations are often irrational (see for example Brunsson, 1985). A question at stake is therefore the extent to which political decisions can be informed by robust information generated by the RBM systems. Moreover, other theories which are more focused on management in complex environments might support efforts in managing towards results. As shown in Table 2, some evaluation recommendations propose incentivising adaptive and flexible management, which is discussed in the next section.

\footnotetext{
${ }^{9}$ This is also in the UN evaluation, where it is stated that reaching stage 5 is challenged and constrained by conceptual, cultural, political, structural and systemic factors and that some of these constraints go beyond the management control of single organisations (UN, 2017b).
} 
Table 2. Solutions and recommendations to RBM challenges and unintended consequences

\begin{tabular}{|c|c|}
\hline $\begin{array}{l}\text { Challenge/unintended } \\
\text { consequence: }\end{array}$ & Solution/Recommendation - as suggested by the evaluation team: \\
\hline Lack of guidance & $\begin{array}{l}\text { - Develop guidance and strategies for RBM with a purpose statement or a theory of } \\
\text { change for RBM } \\
\text {. } \quad \text { Conduct more/new evaluations to assess progress on RBM implementation } \\
\text {. Deliver more training }\end{array}$ \\
\hline Lack of a results culture & $\begin{array}{ll}\cdot & \text { Enhance the mind-set and value systems for RBM } \\
\text { - } & \text { Improve staff commitment to and incentives for RBM } \\
\text { - Stimulate improved leadership and support leadership responsibility } \\
\text { Encourage staff initiative, risk-taking and learning from failure as well as from } \\
\text { success }\end{array}$ \\
\hline $\begin{array}{l}\text { Structural and system } \\
\text { issues }\end{array}$ & 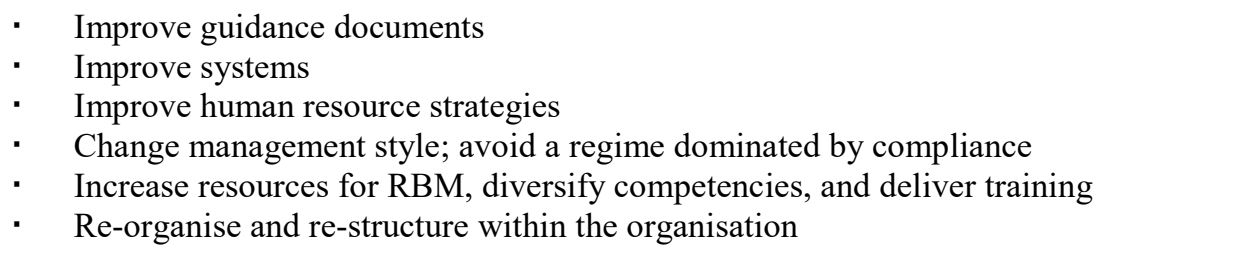 \\
\hline $\begin{array}{l}\text { Measurement and } \\
\text { method issues }\end{array}$ & $\begin{array}{ll}\cdot & \text { Improve measurement systems } \\
\cdot & \text { Increase measurements on different aspects } \\
\text {. } & \text { Introduce quality assurance mechanisms to ensure measurements are robust }\end{array}$ \\
\hline $\begin{array}{l}\text { Ownership and } \\
\text { harmonisation }\end{array}$ & $\begin{array}{ll}\text { - } & \text { Support partners with RBM development } \\
\text { - } & \text { Support partners to develop learning oriented RBM systems } \\
\text {. } & \text { Support and use country-led results frameworks } \\
\text { - } \quad \text { Develop a collective accountability frament at country level } \\
\text {. } \quad \text { Harmonise indicators with those used by partner countries }\end{array}$ \\
\hline Measure fixation & $\begin{array}{l}\text { - } \quad \text { Reduce number of indicators } \\
\text {. }\end{array}$ \\
\hline Suboptimisation & $\begin{array}{l}\text { - Balance benefits and risks for both accountability and learning } \\
\text { - } \quad \text { Assess implementation of the entire RBM system (not only parts) }\end{array}$ \\
\hline $\begin{array}{l}\text { Counterproductive } \\
\text { implementation }\end{array}$ & $\begin{array}{ll}\text { - } & \text { Develop incentive systems that promote innovations } \\
\text { - } & \text { Stimulate management capacities } \\
\text {. } & \text { Entablish joint responsibilities for tasks } \\
\text {. } & \text { Streamline measurement and reporting requirements } \\
\text { - } & \text { Remove requirements (e.g. a logframe) }\end{array}$ \\
\hline
\end{tabular}

\subsection{New approaches}

\subsubsection{Alternative theories and assumptions}

A number of researchers have elaborated alternative concepts for planning, monitoring, evaluation and learning. These concepts aim to address weaknesses in what they consider as fundamental assumptions underpinning classical RBM theory. They suggest using complexity science and adaptive management theory as 'best fit' rather than best practice solutions to support complex development problems (Ramalingam, 2013; Chambers, 2010; Eyben, 2005; Hummelbrunner and Jones, 2013; Patton, 2011; Root et al., 2015; and Honig, 2018). Table 3 summarises these scholars' assumptions in five areas, contrasting 'classical' RBM approaches and new management approaches. 
Table 3. Assumptions underpinning approaches to development co-operation management

\begin{tabular}{|c|c|c|}
\hline $\begin{array}{l}\text { Assumption } \\
\text { area }\end{array}$ & $\begin{array}{l}\text { More like the classical RBM } \\
\text { approach }\end{array}$ & More like an alternative approach \\
\hline $\begin{array}{l}\text { Definition of } \\
\text { problems }\end{array}$ & $\begin{array}{l}\text { Problems can be identified, are } \\
\text { bound and mutually understood; } \\
\text { best practice solutions can be } \\
\text { mutually agreed }\end{array}$ & $\begin{array}{l}\text { Different actors have different understandings of } \\
\text { problems and solutions }\end{array}$ \\
\hline $\begin{array}{l}\text { How change } \\
\text { happens }\end{array}$ & $\begin{array}{l}\text { Linear, proportional, predictable } \\
\text { and controllable }\end{array}$ & $\begin{array}{l}\text { Unpredictable and the result of multiple human } \\
\text { interactions and feedback, shaped by politics and } \\
\text { power }\end{array}$ \\
\hline $\begin{array}{l}\text { Understanding of } \\
\text { knowledge, } \\
\text { learning and } \\
\text { evidence }\end{array}$ & $\begin{array}{l}\text { Objective evidence can be } \\
\text { generated and used to inform } \\
\text { optimal policy options and } \\
\text { programme plans } \\
\text { Rational, behavioural approach to } \\
\text { learning that is a response to top- } \\
\text { down rules and incentives }\end{array}$ & $\begin{array}{l}\text { No knowledge is value free, thus, policy } \\
\text { decisions are based on partial information and } \\
\text { political pressure } \\
\text { Planning is based on consideration of different } \\
\text { scenarios in light of understanding political } \\
\text { context } \\
\text { Local learning from participatory monitoring of } \\
\text { results is key to real-time learning and adaptation } \\
\text { Learners learn and adapt through behavioural, } \\
\text { cognitive and social means }\end{array}$ \\
\hline $\begin{array}{l}\text { Power, } \\
\text { relationships } \\
\text { and } \\
\text { capacities }\end{array}$ & $\begin{array}{l}\text { Formal between atomised } \\
\text { individuals, managed by } \\
\text { contracts and rules } \\
\text { Capacities are easy to organise to } \\
\text { achieve common goals }\end{array}$ & $\begin{array}{l}\text { Informal relationships, trust and flexibility are } \\
\text { important; political and relational skills count } \\
\text { Capacities are distributed so collective action is a } \\
\text { challenge } \\
\text { - Power is everywhere and relationships are messy }\end{array}$ \\
\hline $\begin{array}{l}\text { Management } \\
\text { approach/Roles } \\
\text { and behaviours }\end{array}$ & $\begin{array}{l}\text { Top-down management } \\
\text { Managing and controlling to } \\
\text { satisfy upward accountability and } \\
\text { achieve results } \\
\text { Driven by concerns about } \\
\text { efficiency }\end{array}$ & $\begin{array}{l}\text { Bottom-up approach } \\
\text { Facilitating and trusting, allow discretion and } \\
\text { encourage learning and quality assurance } \\
\text { - Ways of working cannot be dictated from above } \\
\text { More concerned about effectiveness than } \\
\text { efficiency }\end{array}$ \\
\hline
\end{tabular}

Source: adapted from Shutt (2017); Chambers (2010), Ramalingam (2013); Root et al. (2015); Pritchett et al. (2010)

The most common weakness that is pointed to by researchers is on how RBM approaches problems and change in development co-operation. Tools such as the logical framework, commonly used in project planning and monitoring, are criticised for suggesting that complex problems can be commonly understood and defined, and that progress can be predicted and planned. ${ }^{10}$ Alternative management approaches assume that different actors have different understandings of a problem and its solutions. They also note that reality is never linear and possible to predict. High levels of uncertainty must therefore be taken into account and problem solving needs to be locally-led (ODI, 2017b).

Another critique of classical RBM approaches is that they bring about a diminished quality of learning since they prioritise a decontextualised, technical approach to learning, driven by the desire to identify 'best practice' or 'what works' (Chambers, 2010). They tend to exclude the voices of the recipient partners with incentives leading to minimising problems rather than identifying and learning from failure. Alternative approaches propose that learning involves a deeper examination of system dynamics to assess whether goals or strategies are the most appropriate. This would make it possible to test assumptions about whether interventions were the most appropriate when compared with alternate goals and theories of change (Hummelbrunner, 2015). Scholars argue that RBM approaches and tools like the logical framework merely

\footnotetext{
${ }^{10}$ The Theory of Change (TOC) was developed as an alternative to the Logical Framework, focusing on the "pathway of change" rather than giving a fixed picture of how change happens. However, the TOC has been criticised in some literature for having been applied in project management as a donor driven requirement (e.g. Shutt, 2017). This shows that it might not only be the nature of the tool but how the tool is used that matters.
} 
ask the question: 'Are we doing things right to reach the target?' and that such narrow line of questioning excludes possibilities for the kind of double loop learning that is necessary to answer the question: "Are we doing the right thing?' (Shutt, 2016). Moreover, they note that what matters most is who asks the questions, what kinds of knowledge are considered valid and who learns, uses and controls information.

Classical RBM approaches are also criticised for being based on the principal agent theory which assumes that one party is made accountable to another through the use of contracts and performance management tools (Shutt, 2016). Managing and controlling is typically done top-down. Alternative approaches consider that successful development co-operation depends rather on the quality of relationships and the ability of individual staff to improvise and take relational approaches in their work (Eyben, 2010); rules and procedures as well as providers' behaviour need to be more empowering and focusing on mutual learning processes (Chambers, 2010). The emphasis is thus on avoiding provider-driven approaches (Pritchett et al., 2010), which implies putting some distance between the providers and the partners who should be driving reform or change processes (ODI, 2017b).

Despite the differences mentioned above, there are also similarities. The 2002 MfDR guidance from the OECD, for example, promotes learning, dialogue, a flexible approach, analysis of reasons for failure to inform adaptation, importance of keeping measurement simple and ownership aspects. There is nothing inherent in the RBM ideas that prevents joint problem-based action, deeper learning processes, or adaptation of results frameworks to context (Shutt, 2016).

A number of RBM challenges can be understood as problems that arise in practice (Hummelbrunner and Jones, 2013). In particular, RBM was meant to allow teams the flexibility to experiment, adapt and learn, and is hence based on an appreciation that there may not be clear knowledge on how to best achieve an outcome. However, in practice, outputs (and not outcomes or impact) often becomes the focus of RBM efforts (section 2.2.2), outputs being the only measurement teams can control. The approach dis-incentivises learning and innovation. Researchers also argue that RBM was designed to empower different management units, giving the space and responsibilities required to innovate and formulate their own approaches to achieving results. However, in practice, RBM has been implemented in addition to procedural regulations, thereby adding rules and rigidities rather than freeing up space to learn. Many of the problems with RBM could thus be explained by the everlasting difficulty in changing the way organisations work and fully aligning theory to practice.

Other researchers argue that the crucial difference between classical RBM and adaptive management concerns the relationship between ends and means. "In classical RBM the outputs are fully specified at the outset and there is a fixed logic... In an adaptive approach the desired outcomes are fixed but programme outputs are not" (Booth et al., 2018:9). From the outset, the main difference thus lies in the way of deciding, handling and using results information. The principle of setting clear outcome goals and managing for results remains, but the pathway towards achieving the outcome goals and the fixed logic often used is questioned. A driver for the suboptimal implementation of RBM (Box 5) might be the focus on tracking measurable outputs and short term outcomes as well as the perceived need for consistency in these measurements in order to enable comparisons over time and contexts (Kusek and Rist, 2004).

In practice, organisations often apply a mix of management theories. Sound RBM systems could therefore be seen as a way forward for adaptive management. The Sida evaluation argues that RBM is particularly important for projects which are designed to adapt in response to evidence of what works and what does not, and to changes in the context in which they operate (Sida, 2018). Since most RBM systems are actually mixed, the question might not be in shifting from one system to another, but in being open and flexible about how development co-operation is managed in practice.

\subsubsection{New initiatives and methods}

The alternative theories and assumptions have informed a number of emerging methods and global initiatives that aim at shifting from or improving current RBM approaches. These are presented below. 


\section{Initiatives promoting adaptive management}

Adaptive management is a management strategy used to manage uncertainty over time. At its core are flexibility, continuous re-adaptation and programming adjustment depending on context. USAID Learning Lab defines adaptive management as "an intentional approach to making decisions and adjustments in response to new information and changes in context" (USAID, 2017). Adaptive management is not about changing goals during implementation but rather changing the path used to achieve these goals in response to changes. Adaptive management could be captured under the RBM purpose 'direction', which means decision making across all levels of the organisation, i.e. using results information to adapt the programme(s) as needed.

Table 4 summarises new global initiatives promoting adaptive management methods. The first four initiatives (DDD, TWP, GDI and GLAM) have a focus on the whole development sector. GPSA and TA LEARN focus on governance and accountability, and ADAPT, Smart Rules and CLA focus on targeted aspects of development co-operation. All initiatives comprise a mix of providers and practitioners. Three of them are anchored in provider agencies (CLA at USAID, Smart Rules at DFID and GDI at the World Bank).

Table 4. Global initiatives working with adaptive management

\begin{tabular}{|c|c|}
\hline Initiative & What is it? \\
\hline $\begin{array}{l}\text { Doing Development } \\
\text { Differently (DDD) }\end{array}$ & $\begin{array}{l}\text { Community of researchers and practitioners convened by the Overseas } \\
\text { Development Institute (ODI) and Harvard's Kennedy School. A core manifesto } \\
\text { calling for development to focus on locally defined problems, tackled through } \\
\text { iteration, learning, and adaptation. }\end{array}$ \\
\hline $\begin{array}{l}\text { Thinking and Working } \\
\text { Politically (TWP) }\end{array}$ & $\begin{array}{l}\text { Semi-regular conventions of representatives from various providers, think tanks, } \\
\text { and international NGOs that discuss the use of politically aware approaches to aid } \\
\text { and development. }\end{array}$ \\
\hline $\begin{array}{l}\text { Global Delivery Initiative } \\
\text { (GDI) }\end{array}$ & $\begin{array}{l}\text { Cross-provider collaborative (spearheaded by the World Bank, which currently } \\
\text { serves as the Secretariat) to deepen the know-how for effective operational delivery } \\
\text { of aid and development. }\end{array}$ \\
\hline $\begin{array}{l}\text { The Global Learning for } \\
\text { Adaptive Management } \\
\text { initiative (GLAM) }\end{array}$ & $\begin{array}{l}\text { A global network learning alliance that aims to actively identify, operationalise and } \\
\text { promote rigorous evidence-based approaches to adaptive management funded by } \\
\text { DFID and USAID and hosted at ODI. Rolled out in } 2018 \text {. }\end{array}$ \\
\hline LearnAdapt & $\begin{array}{l}\text { Collaboration between DFID, ODI and Brink, to explore how to better manage } \\
\text { adaptive programmes. Sister project of GLAM and hosted at ODI. Rolled out in } \\
2018 \text {. }\end{array}$ \\
\hline $\begin{array}{l}\text { Global Partnership for } \\
\text { Social Accountability } \\
\text { (GPSA) }\end{array}$ & $\begin{array}{l}\text { Funds and convenes CSOs and governments on social accountability initiatives. } \\
\text { Established by the World Bank in } 2012 .\end{array}$ \\
\hline TA LEARN & $\begin{array}{l}\text { Community of practice composed of transparency and accountability practitioners } \\
\text { from many countries. }\end{array}$ \\
\hline $\begin{array}{l}\text { ADAPT (analysis driven } \\
\text { agile programming } \\
\text { techniques) }\end{array}$ & $\begin{array}{l}\text { Collaboration of two major NGOs (Mercy Corps and International Rescue } \\
\text { Committee) with aim to identify, develop, and spread the use of adaptive } \\
\text { management approaches in complex aid and development projects. }\end{array}$ \\
\hline Smart Rules & $\begin{array}{l}\text { DFID's internal operating framework for programmes, emphasizing how the } \\
\text { agency adapts to and influences local context. Rolled out in } 2014 \text {. }\end{array}$ \\
\hline $\begin{array}{l}\text { Collaborating, Learning, and } \\
\text { Adapting (CLA) }\end{array}$ & $\begin{array}{l}\text { USAID's framework and internal change efforts for incorporating collaboration, } \\
\text { learning, and adaptation at its missions and with implementing partners. }\end{array}$ \\
\hline
\end{tabular}

Source: Adapted from Algoso and Hudson, 2016

The initiatives consider adaptive management and learning in different ways. Algoso and Hudson have distinguished between adaptive learning as "all about it", i.e. central to better development co-operation which is the case for the ADAPT initiative, or "tactic only", i.e. used to tweak existing approaches within providers, as is the case for DFID's smart rules initiative. 
Algoso and Hudson have also differentiated whether the approaches have a "revolutionary uptake", i.e. whether they propose a wholesale shift away from traditional aid approaches or whether the initiatives have an "evolutionary uptake" and thereby give more attention to politics within traditional aid approaches. The Doing Development Differently initiative is an approach that has a "revolutionary uptake" while stressing that adaptive learning is central to improve development co-operation. The initiative has two main foundations: the first is to move to locally-led problem solving, meaning that change is best led from within, and is weakened when it is externally-driven, purposely or otherwise (ODI, 2017b); the second is to continuously re-adapt focus during implementation: instead of delivering activities determined at the outset, programmes should identify core needs and test workable solutions. This means that programmes (or portfolios of programmes) should have clear goals or objectives, in terms of their contribution to improve development outcomes that are set out and agreed in advance. However, the means for achieving these goals - the activities and outputs, or what a given intervention commits to producing - cannot be specified in similarly concrete terms. Instead, what needs to be clearly articulated at the outset is a structured process for testing and learning to discover what will work best to achieve these aims ('learning by doing)'. What exactly gets done, and by when, is open to change, based on the findings of the testing process, as opposed to relying on a detailed plan developed ex ante (ODI, 2017b).

All the initiatives promote or use different methods or approaches to tackle complexity and uncertainty. Both the DDD and TWP for example promote and use a Problem Driven Iterative Approach (PDIA). Instead of assuming that actors have a mutual understanding of problems that can be tackled by proposing predefined technical solutions with predictable results, PDIA aims to develop contextually relevant solutions to locally defined problems (OECD, 2015).

As already mentioned, many providers claim that they practice adaptive management - at least to a certain extent. As suggested in a recent blog, the following questions can help to know the extent to which a programme is really adaptive or if it is just "old wine in new bottles" (Christie et al., 2018):

i. Is there a shared understanding of why programming is taking an adaptive approach?

ii. Is there a shared understanding of and commitment to adaptive programming in practice?

iii. How flexible are management systems?

iv. Is there a commitment to working with the right people?

v. Is there an organisational culture of learning?

vi. Is there an ability to tell honestly the story and learning journey behind results?

Other initiatives

Other initiatives and networks focus on improving current RBM methods. They include in particular:

- The CLEAR (Centers for Learning on Evaluation and Results) initiative, which aims to improve policy decisions through strengthening monitoring and evaluation systems and capacities. The initiative is a joint programme of academic institutions and providers (multilateral banks, Australia, Belgium, Sweden, Switzerland and the United Kingdom).

- The network Better Evaluation promotes outcome mapping and outcome harvesting, two methods that have been tried and used by providers such as Sida and International IDEA. Whilst outcome mapping is a methodology for planning, monitoring and evaluating behavioural change and the strategies to support those changes in development initiatives, outcome harvesting can be used in evaluations to verify and interpret outcomes in contexts where relations of cause and effect are not fully understood. Outcome harvesting tracks evidence on what has changed - outcomes - and then works backwards to determine whether and how an intervention has contributed to these changes. 


\subsubsection{Evidence related to the new approaches shows mixed results}

The literature offers evidence and support for factors that are promoted by the new approaches, in particular as regards adaptive management (Box 7). A recent study drawing on a database of over 14000 discrete development projects from nine providers (GIZ, KfW, IFAD, DFID, GFATM, JICA, EC, WB and AsDB) concludes that providers do benefit from adaptive management and from decentralising planning and decision-making authority to field offices (Honig, 2018). Tight controls and focus on reaching pre-set measurable targets prevent staff from using skills, local knowledge and creativity to solve problems and maximise the impact of development co-operation. Meanwhile project outcomes improve when decisionmaking authority is placed as close to frontline staff and local partners as possible.

\section{Box 7: Evidence for collaborating, learning and adapting}

The USAID Learning Lab has conducted a broad literature review on whether collaborating, learning and adapting can make a difference to organisational effectiveness and development results. It found twelve positive findings:

1. Strategic collaboration improves performance.

2. Taking time to pause and reflect on the work is critical for learning and improving performance.

3. Continuous learning is linked with job satisfaction, empowerment, employee engagement and ultimately, improved performance and outcomes.

4. Quality knowledge management (KM) systems have a significant and positive impact on project performance.

5. M\&E are both positively and significantly associated with achieving development outcomes when incorporated into programme management and designed to support learning and decision-making.

6. Adaptive management contributes to sustainable development particularly when it has leadership support, public support, and an adequate investment of time.

7. Locally-led development is most effective.

8. Managing adaptively is more likely to improve outcomes when decision-making autonomy is placed as close as possible to frontline staff and local partners.

9. Evidence-based decision making is more likely to occur when decision makers demand, define and interpret evidence.

10. Leaders are essential in creating a learning culture, the foundation of learning organisations.

11. Teams that have high levels of trust and psychological safety tend to be better at learning and adapting.

12. Individuals who are curious, have growth mind-sets, and are able to empathize with their colleagues are generally better able to adapt to changing circumstances. (USAID, 2017)

Source: USAID, 2017

However, several studies show that new approaches also face challenges in their implementation. Shutt, who has tried to summarise some evaluations and findings from providers using new approaches concludes that "efforts to enhance results through these alternative methods have not lived up to expectations" (Shutt, 2016:67). She notes that the few examples of success often "raise age old questions about whether performance monitoring systems are going to run in parallel with learning systems, generating data that is only useful for political accountability and for managers or researchers interested in performance management" (Shutt, 2016:68). Moreover, new approaches such as Doing Development Differently (DDD) and Thinking and Working Politically (TWP) seem to be more staff intensive and skill intensive than classical results-based management (Green, 2017); staff must be able to read the vagaries of the domestic political economy in real time and respond appropriately, which requires technical depth, political skills and solid experience.

More recently, several scholars have emphasised the role of trust in supporting learning and adaptation (USAID, 2017; Honig, 2018; Honig \& Gulrajani, 2018; Bringselius, 2018). Employees' trust in their organisations, employees' trust of one another and trust by political authorities are all associated with better 
organisational performance. Trust can be a virtuous cycle under certain conditions, with a trusting relationship between service providers and monitoring services motivating better performance, as well as further trust. Trust could reduce the need for targets, indicators and continuous performance measurement. On the contrary, lack of trust or low trust can explain why a number of adaptive management approaches do not work (Green, 2018). In Sweden, Trust Based Management is currently seen as an alternative to the New Public Management paradigm. ${ }^{11}$

The elements above show that there is no clear evidence on which management approaches work best, all approaches coming with their challenges when implemented. A question is then in what way the theories and methods underlying new initiatives help to improve managing for development results. Honig and Gulrajani (2018) respond to this question in presenting three main lessons from the new approaches:

1. Provider agencies need to focus on better understanding the local contexts in which they operate;

2. Providers' interventions need to be adapted or tailored to local contexts based on features of the context during project design;

3. As contexts change, so must providers' interventions. Organisations must be flexible enough to allow re-adaptation in response to exogenous shocks and performance feedback.

The classical RBM approaches do not run against these lessons. However, in practice, the focus tends to be on quantitative measurements, indicators, and proving causality, which often impedes adaptation, and causes challenges and unintended consequences. Therefore, the three lessons above could be considered as important for any management strategy chosen by a provider.

\section{Conclusion}

\subsection{Adapting the management model to each context and authorising environment}

Development co-operation contexts differ. Problems are not the same in Afghanistan as they are in Tanzania. Moreover, some projects are obviously 'simpler' than others in terms of actors' perceptions of the problems that a project addresses, their ability to get together, and what is known about the causal mechanisms that determine whether proposed 'solutions' will work or not in a given context. Different scholars have therefore proposed that organisations choose the management model that will serve them best depending on context and type of project. Honig, for example, proposes a model of "navigation by judgement", i.e. relying on: i) agents' own judgement as the preferred model when predictability of the environment and verifiability of projects is low; and ii) top-down models, which often means reporting against quantitative output targets, as the preferred model in highly predictable environments and highly verifiable projects. Honig shows that in navigation by judgement, returns in terms of project outcomes are in fact greater for projects in less predictable environments (Honig, 2018).

Such new approaches remain so far implemented as small scale, pilot initiatives and operate in the same broader organisational and bureaucratic environment, e.g. with the same incentive systems. With staff autonomy, motivation and trust being key factors to support organisational change, broader changes in how agents are evaluated and promoted are needed. Provider organisations need to respond better to both environmental context and internal organisational behaviours.

\footnotetext{
${ }^{11}$ Although trust and control may be seen as opposite, control and measurement (as in RBM methods) may in some cases foster trust rather than distrust. A clear contract and straightforward communication may for example be valued in cases of complexity and ambiguity. There are also some dilemmas with trust; in particular trustful relationships require a sense of closeness and like-mindedness, which might contradict the DDD prerequisite of an "arms lengths" distance between the donor and the recipients in planning and monitoring interventions.
} 
Such organisational changes might depend on each organisation's authorising environments. Factors such as the organisation's history and institutional structure affect both the chosen management approach as well as how well the organisation succeeds. As an illustration, the UN funds, because of their governance structures, sources and types of funding, and accountability requirements cannot manage for results in the same way as a bilateral development co-operation agency does, which is accountable to its domestic constituencies.

Organisations also need to manage risks better, and this also depends on the authorising environment. Providers with insecure authorising environments are associated with less risk-taking, greater principal control, and greater use of "legitimacy-seeking output measurement" (Honig, 2018). Commonly, when the level of ODA is under threat, providers do what they believe is the most appropriate to re-gain public and political support, e.g. collecting data against standard indicators to demonstrate the scale and reach of their programmes. However, this adaptation can "prompt international development organisations to get 'navigation strategy' wrong", leading to management strategies which only comply with what they believe is expected from them and what will support their survival, and not a management strategy that supports them to achieve their organisational goals (Honig, 2018:41).

This review has shown that accountability to domestic and international constituencies is the principal driver for how RBM internal systems have evolved. RBM reforms have translated into a disproportionate focus on accountability and the belief that communication in the form of simple measurable facts will lead to increased trust and legitimacy. This lack of balance is probably the main explanation of the unintended consequences of RBM. Therefore, in order for providers to free up time and space for working with internal matters, such as choosing their navigation strategy, they would need to build a "shield" against external pressure. This would allow them to not always answer to the accountability pressure first, but rather do what they often implicitly know is best for the achievement of development results.

\subsection{Getting the right narrative and enhancing communication}

A challenge for providers is thus to build a narrative and a communication approach explaining how development co-operation works and the conditions in which it supports development. There is limited research on whether and how different kinds of messaging influence public support and understanding of development co-operation. Some research suggests that those who support development co-operation would like a more nuanced explanation of what is done (Glennie et al., 2013), and that there is a public fatigue with messages about need (Wild et al., 2015). Both the UN and the SDC evaluation discuss the effectiveness of reporting to the public. Does all the reporting actually affect public opinions of aid? And would they be equally satisfied with qualitative reporting? The SDC evaluation states that: "much is done in the name of domestic accountability, even if the effectiveness of corporate communications for this purpose remain largely unknown" (SDC, 2017:iv). Similarly, the UN evaluation notes that the public does not only desire numbers but more qualitative information about the development process and the complexities involved in achieving results (UN, 2017b:xi).

According to the OECD Development Communications Network, "data are an essential part of development communications, but narratives and emotions help bring them to life" (OECD, 2017d). Effective communication to external audiences could save time for aid providers and they would have more freedom to navigate among different management approaches. The Network promotes five principles for effective communication:

1. Craft results messages that appeal to both hearts and minds. Citizens want to hear the real stories behind development. Numbers alone will not resonate with most people.

2. Choose results messengers to whom people can relate. Citizens want to hear from the beneficiaries of aid or from passionate field workers, not just politicians, diplomats or celebrities.

3. Use countries' own frameworks to find results data and stories. The most compelling stories come from the programmes and projects that local actors care about. 
4. Build public trust over time by telling it how it is: development is complicated, risky and long term. Providers need a confident, but humbler, narrative about the role and impact of aid.

5. Use data to understand targeted audiences. Web analytics, public attitudes research and consultations can shed light on how to reach different constituencies. They can also tell communicators whether their work has been effective

Meanwhile providers should keep in mind the potential of the SDGs for communication purposes. As was noted at the October 2017 workshop of the OECD/DAC Results Community, they "represent a rallying point for communication about development results and can link the efforts of providers, partners and other stakeholders. Most of the SDG targets and priorities deal with real-life change for people, communities, countries and planet earth. They are globally known and brand recognition is high, and therefore promise to be a unique opportunity for communication about results" (OECD, 2017e).

\subsection{Balancing the various objectives of results-based management}

Adaptation to what happens in practice is important also at corporate level. A theory of change capturing how different aid channels (bilateral and multilateral) and instruments will contribute to the overall objectives set for the development co-operation programme could be supportive for an increased understanding on how results from different levels contribute to the achievement of development results on the ground. Meanwhile management needs to set clear priorities, develop adequate guidance and provide appropriate incentives to manage the potential tensions between the different purpose of RBM - accountability, communication, decision-making and learning - and promote an organisational culture focused on learning and results. This will help to resist the temptation to favour easy-to-capture targets and indicators, and focus on the longerterm outcomes that will contribute to sustainable development. Valuing qualitative evidence alongside quantitative data is important: using qualitative data and stories to triangulate and support quantitative data will enable to produce an accurate and communicable picture of the achievements of the development cooperation programme.

The OECD will continue to work through the OECD/DAC Results Community to discuss and debate these findings and their implications. While recognising the variety of management practices and acknowledging that there is not a 'one-size-fits-all' approach, given that organisations operate in various environments and are subject to different governing processes, this review invites stakeholders to revisit their approach to RBM. Backed by in-depth discussions within the OECD/DAC Results Community and a consultative process to involve a broader range of stakeholders, such a fresh look should lead to a shared understanding of the key building blocks that need to be in place to best manage, achieve and demonstrate how development interventions contribute to sustainable development results. This will in turn lead to the development of a core set of widely endorsed guiding principles for RBM in development co-operation. The Results team, in consultation with the Reference Group, will conduct and manage this participatory process over 2019. 


\section{References}

AFDB (2018a), Evaluation of Quality Assurance at the African Development Bank: Promoting Accountability and Learning for Development Effectiveness, IDEV, Independent Development Evaluation, African Development Bank (AfDB), http://idev.afdb.org/en/document/independent-evaluation-qualityassurance-across-project-cycle-african-development-bank.

AFDB (2018b), Independent Evaluation of Quality Assurance across the Project Cycle of the African Development Bank (2012-2017). IDEV, Independent Development Evaluation, African Development Bank (AfDB), http://idev.afdb.org/en/document/independent-evaluation-quality-assurance-across-project-cycleafrican-development-bank.

Algoso, D. and A. Hudson (2016), "Where have we got to on adaptive learning, thinking and working politically, doing development differently etc? Getting beyond the People's Front of Judea", https://oxfamblogs.org/fp2p/where-have-we-got-to-on-adaptive-learning-thinking-and-working-politicallydoing-development-differently-etc-getting-beyond-the-peoples-front-of-judea/.

Andrews, M., L. Pritchett and M. Woolcock (2012), "Escaping capability traps through problem driven iterative adaptation (PDIA)", WIDER Working Paper, No. 2012/064, Helsinki: UNU-WIDER.

Booth, D., K. Balfe, R. Gallagher, G. Kilcullen, S. O’Boyle and A. Tiernan (2018), "Learning to make a difference Christian Aid Ireland's adaptive programme management in governance, gender, peace building and human rights", Overseas Development Institute, Christian Aid, Irish Aid.

Bringselius, L. (2018) (red.) Styra och leda med tillit: forskning och praktik, SOU 2018:38. Stockholm: regeringskansliet / Norstedts Juridik.

Brunsson, N. (1985), The irrational organization. Irrationality as a Basis for Organizational Action and Change. Wiley and sons.

Chambers, R. (2010), “Paradigms, poverty and adaptive pluralism”, IDS Working Paper No. 334, Brighton, UK: Institute of Development Studies.

Christie, A., Derbyshire, H., Fisher, A., Fraser, S., Mwamba, W. (2018), Old Wine in New Bottles? 6 ways to tell if a programme is really 'doing development differently', https://oxfamblogs.org/fp2p/oldwine-in-new-bottles-6-ways-to-tell-if-a-programme-is-really-doing-development-differently/.

CGIAR (2017), Evaluation of Results-Based Management in CGIAR, Vanderberg, Wigboldus.

Diefenbach, T. (2009), "New public management in public sector organizations: the dark sides of managerialistic "enlightenment", Public administration, Vol. 87/4, pp. 892-909.

Glennie, J., A. McKechnie, G. Rabinowitz and A. Ali (2013), "Localising aid: Sustaining change in the public, private and civil society sectors. Centre for Aid and Public Expenditure", London, UK: Overseas Development Institute.

Green, D. (2015) "Where have we got to on 'results-based aid', 'cash on delivery' etc.", https://assets.publishing.service.gov.uk/government/uploads/system/uploads/attachment_data/file/684278/f ull-report-UEA2-merged.pdf.

Green, D. (2017), "So is 'Doing Development Differently' a movement now? And if so, where's it going?", https://oxfamblogs.org/fp2p/so-is-doing-development-differently-a-movement-now-and-if-sowheres-it-going/.

Green, D. (2018), "Adaptive Management: the trade-offs; how to build trust; the sources of resistance and how to counter them", https://oxfamblogs.org/fp2p/adaptive-management-the-trade-offs-how-to-buildtrust-the-sources-of-resistance-and-how-to-counter-them/. 
EU (2017) Analysis of the use of Joint Results Frameworks in EU Joint Programming, European Union, https://europa.eu/capacity4dev/joint-programming/documents/report-joint-results-framework-jointprogramming.

Eyben, R. (2005), “Donors' learning difficulties: Results, relationships and responsibilities”, IDS Bulletin, Vol. 36/3, pp.98-107.

Finland (2011). Evaluation of Results-Based Approach in Finnish Development Cooperation. Evaluation report 2011:2. Ministry for Foreign Affairs of Finland, Helsinki. By: Poate, D., Bartholomew. A, Rothmann, I. \& Palom.ki, A.

Finland (2015), Evaluation on Finland's Development Policy Programmes from a Results-Based Management Point of View 2003-2013, Ministry for Foreign Affairs of Finland.

http://formin.finland.fi/public/default.aspx? contentid $=322204 \&$ nodeid $=49728 \&$ contentlan $=2 \&$ culture $=$ enUS.

Finland (2018a), Meta-evaluation of Project and Programme Evaluations in 2015-2017 - Evaluation on Finland's Development Policy and Cooperation, Ministry for Foreign Affairs of Finland.

Finland (2018b): Terms of Reference of the evaluation on knowledge management, decision making and learning "How do we learn, manage and make decisions in Finland's development policy and cooperation?" Ministry for Foreign Affairs of Finland

GAC (2017), Synthesis of Evaluations of Grants and Contributions Programming funded by the International Assistance Envelope, 2011-2016, Global Affairs Canada, http://international.gc.ca/gacamc/publications/evaluation/2016/evaluations_grantsevaluations_subventions.aspx?lang=eng.

GAO (2017), Foreign Assistance: Agencies can Improve the Quality and Dissemination of Program Evaluations, United States Government and Accountability Office.

https://www.gao.gov/assets/690/683156.pdf.

GEF (2017), Review of Results-Based Management in the GEF, Independent Evaluation Office, Global Environment facility, November 2017. http://www.gefieo.org/sites/default/files/ieo/evaluations/files/rbmstudy-2017_2.pdf.

Holzapfel, S. (2016), "Boosting or hindering aid effectiveness? An assessment of systems for measuring donor agency results", Public Administration and Development, Vol. 36/1, pp. 3-19.

Honig, D. and N. Gulrajani (2018), "Making good on donors' desire to Do Development Differently", Third World Quarterly, Vol. 39/1, pp. 68-84.

Honig, D. (2018), Navigation by Judgement - Why and When Top Down Management of Foreign Aid Doesn't Work. Oxford: Oxford University Press.

Hummelbrunner, R. and H. Jones (2013), "A Guide for Managing in the Face of Complexity", Overseas Development Institute Working Paper, London, UK.

Hummelbrunner, R. (2015), "Learning, Systems Concepts and Values in Evaluation: Proposal for an Exploratory Framework to Improve Coherence", IDS Bulletin, Vol. 46/1, pp.17-29.

IAD (2015), Final Report on an Advisory Review of the Information Quality Supporting the World Bank's Portfolio Monitoring. World Bank Publications, Washington.

ICAI (2015), DFID's Approach to Delivering Impact, Independent Commission for Aid Impact, http://icai.independent.gov.uk/wp-content/uploads/ICAI-report-DFIDs-approach-to-Delivering-Impact.pdf.

Jacobsson, B., Pierre, J., \& Sundström, G. (2015), Governing the embedded state: The organizational dimension of governance, OUP Oxford.

Kusek, J. Z. and R.C. Rist (2004), Ten steps to a results-based monitoring and evaluation system: A handbook for development practitioners. World Bank Publications, Washington. 
Mayne, J. (2007). Challenges and lessons in implementing results-based management, Evaluation, 13(1), 87-109.

Meier, W. (2003), "Results Based Management: Towards a Common Understanding among Development Cooperation Agencies", Discussion paper prepared for the Canadian International Development Agency, Performance Review Branch, for consideration by the DAC Working Party on Aid Effectiveness and Harmonization, Ottawa, Canada.

Norad (2015), Experiences with Results-Based Payments in Norwegian Development Aid, Evaluation Department, Report No. 4/2015. https://www.Norad.no/globalassets/publikasjoner/publikasjoner-2015levaluering/experiences-with-results-based-payments-in-norwegian-development-aid/experiences-withresults-based-payments--in-norwegian-development-aid.pdf.

Norad (2018a), The Quality of Reviews and Decentralised Evaluations in Norwegian Development Cooperation, Evaluation Department, Report No. 1/2017 https://www.Norad.no/contentassets/4/thequality-of-reviews-and-decentralised-evaluations-in-norwegian-development-cooperation.pdf.

OECD (2002), Glossary on key terms in evaluation and results based management, OECD Publishing, Paris.

OECD/DAC (2006), Sourcebook on Managing for Development Results, OECD Publishing, Paris.

OECD (2014), Measuring and managing results in development co-operation. A review of challenges and practices among DAC members and observers, OECD Publishing, Paris, http://www.oecd.org/dac/results-development/docs/Measuring-and-managing-results.pdf.

OECD (2015), A governance practitioner's notebook - Alternative ideas and approaches, Building capacity by delivering results - Putting PDIA principles into practice, OECD Publishing, Paris, https://www.oecd.org/dac/accountable-effectiveinstitutions/Governance \%20Notebook\%202.3\%20Andrews\%20t\%20al.pdf.

OECD (2016), Providers' use of results information for accountability, communication, direction and learning. Survey Results, OECD Publishing, Paris.

OECD (2017a), Strengthening the results chain: synthesis of case studies of results-based management by providers, OECD Publishing, Paris, https://read.oecd-ilibrary.org/development/strengthening-the-resultschain 544032a1-en\#page1.

OECD (2017b), Development Co-operation Report 2017. Data for development, OECD Publishing, Paris, https://www.oecd-ilibrary.org/development/development-co-operation-report-2017_dcr-2017-en.

OECD (2017c), DAC Peer review synthesis note - Results-based management and evaluation, Paris. (Not published)

OECD (2017d), Communicating About Development Results: Not just numbers. Dev Com contribution to the Development Co-operation Report 2017, Data for Development, OECD, Paris.

OECD (2017e), Key messages, OECD/DAC Results Community Workshop, October 2017, OECD, http://www.oecd.org/dac/results-development/docs/Results-oct-2017-Key-Messages.pdf.

OECD (2018a), "Is the results community ready and fit to embrace the data revolution?", Discussion paper for the OECD/DAC Results Community Workshop, 10-11 April, 2018, Paris, http://www.oecd.org/dac/results-development/docs/results-data-results-workshop-apr-18.pdf.

OECD (2018b), "Measuring the results of private sector engagement through development cooperation", Discussion paper for the OECD/DAC Results Community Workshop, 10-11 April 2018, Paris, http://www.oecd.org/dac/results-development/docs/results-pse-results-workshop-apr-18.pdf.

ODI (2017a), The politics of the results agenda in DFID: 1997-2017, Research reports and studies, Craig Valters and Brendan Whitty. https://www.odi.org/publications/10902-politics-results-agenda-DFID$\underline{1997-2017 .}$ 
ODI (2017b), Putting theory into practice. How DFID is doing development differently. Wild L, Booth $\mathrm{D}$, and Walters $\mathrm{C}$.

Patton, M. Q. (2011), Developmental evaluation: Applying complexity concepts to enhance innovation and use, New York City, USA: Guilford Press.

Pritchett, L., M. Woolcock and M. Andrews (2010), "Capability traps? The mechanisms of persistent implementation failure", Center for Global Development Working Paper, No. 234. 51.

Raimondo, E. (2016), "What difference Does Good Monitoring and Evaluation Make to World Bank Project Performance?", Policy Research Working Paper, No. 7726, World Bank Publications.

Ramalingam, B. (2013), Aid on the Edge of Chaos. Oxford, UK: Oxford University Press.

Root, H., H. Jones and L. Wild, (2015), Managing Complexity and Uncertainty in Development Policy and Practice. Report. London, UK: Overseas Development Institute.

Savedoff, W. and R. Perakis (2014), Payment by Results: One size doesn't fit all. https://www.cgdev.org/blog/payment-results-one-size-doesnt-fit-all.

SDC (2014). SDC Quality Assurance Medium Term Programme 2014-2017.

SDC (2017). Independent Evaluation of SDC's Results-Based Management System with a Focus on Poverty Reduction, Evaluation 2017/4, Swiss Agency for Development and Cooperation, SPM Consultants. https://www.newsd.admin.ch/newsd/NSBExterneStudien/855/attachment/en/3685.pdf

Shamash, L., S. Burall and B. Whitty (2013), Resetting the aid relationship. Involve.

Shutt, Cathy (2016), Towards an alternative development management paradigm. Expert group on Aid Studies, Report No. 7, Sweden.

Sida (2018). Evaluation of the market systems development approach - Lessons for expanded use and adaptive management at Sida. Itad. Forthcoming.

Smith, P. (1995), "On the unintended consequences of publishing performance data in the public sector", International journal of public administration, Vol. 18/2-3, pp. 277-310.

UN (2017a), Results-Based management in the United Nations Development System - Analysis of Progress and policy effectiveness, Summary Report, Sukai Prom-Jackson, Joint Inspection Unit of the United Nations, Geneva, https://www.unjiu.org/sites/www.unjiu.org/files/jiu_rep_2017_6_english_0.pdf.

UN (2017b), Results-Based Management in the United Nations Development System - Analysis of Progress and policy effectiveness, Full Report, Sukai Prom-Jackson, Joint Inspection Unit of the United Nations, Geneva, https://www.unjiu.org/sites/www.unjiu.org/files/rbm_full_report_english.pdf.

UN (2017c), Results-Based Management in the United Nations Systems - High-Impact Model for Results-Based management - Benchmarking framework, stages of development and outcomes, Sukai PromJackson, Joint Inspection Unit of the United Nations, Geneva, https://www.unjiu.org/sites/www.unjiu.org/files/jiu_note 2017_1_english_0.pdf.

US (2015), US Department of State, Evaluation of the Office of U.S. Foreign Assistance Resources' Implementation of the Managing For Results Framework - Evaluation Report, https://www.state.gov/documents/organization/251381.pdf.

USAID (2016), Evaluation Utilisation at USAID, https://pdf.usaid.gov/pdf docs/pa00kxvt.pdf.

USAID (2017), Evidence base for collaborating, learning and adapting - Summary of literature review,

https://usaidlearninglab.org/sites/default/files/resource/files/eb4cla_summary_literaturereview 20171020_fi nal.pdf.

USAID (2018), What is adaptive management?, https://usaidlearninglab.org/lab-notes/what-adaptivemanagement- 0. 
Van Thiel, S. and F. L. Leeuw (2002), The performance paradox in the public sector, Public Performance \& Management Review, Vol. 25/3, pp. 267-281.

Wild, L., D. Booth, C. Cummings, M. Foresti and J. Wales (2015), Adapting development: Improving services to the poor, Report, London: Overseas Development Institute.

WB (2016), Behind the Mirror - A Report on the Self-Evaluation Systems of the World Bank, Independent Evaluation Group, IEG, World Bank Publications, http://documents.worldbank.org/curated/en/902331469736885125/pdf/107274-WP-REVISEDPUBLIC.pdf

WB (2017), Results and the Performance of the World Bank Group 2016, World Bank Group, Independent Evaluation Group, IEG, World Bank Publications, http://ieg.worldbankgroup.org/sites/default/files/Data/Evaluation/files/rap2016.pdf.

Vähämäki, J., M. Schmidt and J. Molander (2011), Results based management in development cooperation, Riksbankens Jubileumsfond, Stockholm.

Vähämäki, J. (2017), Matrixing aid: the rise and fall of 'results initiatives' in Swedish development aid. Doctoral dissertation, Stockholm Business School, Stockholm University. 


\section{Annex 1}

Table 1. Evaluations on RBM performance in donor agencies

\begin{tabular}{|c|c|c|c|}
\hline $\begin{array}{l}\text { Organisation } \\
\text { Title of evaluation } \\
\text { Evaluator }\end{array}$ & $\begin{array}{l}\text { Purpose/context of } \\
\text { evaluation: }\end{array}$ & Method: & $\begin{array}{l}\text { Earlier RBM } \\
\text { evaluations/reviews }\end{array}$ \\
\hline $\begin{array}{l}\text { United Nations (UN) } \\
\text { RBM in the UN } \\
\text { Development System - } \\
\text { Analysis of progress and } \\
\text { policy effectiveness. } 2017 . \\
\text { JIU (Joint Inspection Unit } \\
\text { of the United Nations } \\
\text { System) }\end{array}$ & $\begin{array}{l}\text { To conduct a system-wide } \\
\text { review of results-based } \\
\text { management. } \\
\text { Step wise process: } 1^{\text {st }} \text { step: } \\
\text { development of RBM model, } \\
2^{\text {nd }} \text { step: Review of progress } \\
\text { against the model }\end{array}$ & $\begin{array}{l}\text { Analysis made against a high } \\
\text { impact RBM model with a } \\
\text { benchmarking framework to } \\
\text { define its mainstreaming and } \\
\text { the methodology to assess its } \\
\text { stages of development and } \\
\text { outcomes. }\end{array}$ & $\begin{array}{l}\text { Evaluation conducted in } \\
2015 \text { and } 2008\end{array}$ \\
\hline $\begin{array}{l}\text { Global Environment } \\
\text { Facility (GEF) } \\
\text { Review of RBM in the } \\
\text { GEF. } 2017 . \\
\text { GEF Independent } \\
\text { Evaluation Office }\end{array}$ & $\begin{array}{l}\text { The extent to which the GEF } \\
\text { RBM system captures key } \\
\text { results of GEF activities and } \\
\text { promotes adaptive } \\
\text { management. }\end{array}$ & $\begin{array}{l}\text { Survey of GEF documents } \\
\text { and literature, analysis of } \\
\text { Project Management } \\
\text { Information Systems and } \\
\text { Independent Evaluation } \\
\text { Office datasets, semi- } \\
\text { structured interviews of key } \\
\text { informants. }\end{array}$ & $\begin{array}{l}\text { Evaluation conducted in } \\
1994, \text { follow up in } 2013 .\end{array}$ \\
\hline $\begin{array}{l}\text { Finland } \\
\text { Finland's Development } \\
\text { policy programmes from a } \\
\text { results-based management } \\
\text { point of view 2003-2013. } \\
2015 . \\
\text { Ministry for Foreign } \\
\text { Affairs }\end{array}$ & $\begin{array}{l}\text { How the Finnish Development } \\
\text { Policy Programmes of 2004, } \\
2007 \text { and } 2012 \text { have defined } \\
\text { results-based development } \\
\text { policy and cooperation. } \\
\text { To promote thinking on the } \\
\text { holistic development policy } \\
\text { level of RBM }\end{array}$ & $\begin{array}{l}\text { Review of three Policy } \\
\text { Programmes of 2004, } 2007 \\
\text { and } 2012 \text {. } \\
\text { Interviews and document } \\
\text { study. }\end{array}$ & $\begin{array}{l}\text { Evaluation conducted in } \\
2011 \text { (focus on project level } \\
\text { RBM). Metaevaluation on } \\
\text { evaluation use in } 2012 \text {. } \\
\text { Metaevaluation on } \\
\text { evaluation use in } 2018 \text {. }\end{array}$ \\
\hline $\begin{array}{l}\text { NORAD } \\
\text { The aid administration's } \\
\text { practice of results-based } \\
\text { management } \\
\text { Itad in association with } \\
\text { Chr. Michelsen Institute }\end{array}$ & $\begin{array}{l}\text { To understand how RBM has } \\
\text { been operationalized; to } \\
\text { understand the consequences } \\
\text { of the current RBM approach; } \\
\text { to look at how RBM } \\
\text { contributes (or not) to } \\
\text { development outcomes. }\end{array}$ & $\begin{array}{l}\text { Both MFA and Norad and } \\
\text { their support to CSOs. } \\
\text { In three levels: Strategic } \\
\text { level, Portfolio level } \\
\text { and Grant level } \\
\text { Multiple sources, } 90 \\
\text { interviews. }\end{array}$ & RBM evaluation in 2014 \\
\hline $\begin{array}{l}\text { World Bank } \\
\text { Results and Performance of } \\
\text { the World Bank Group. } \\
2016 \\
\text { Independent Evaluation } \\
\text { Group (IEG) }\end{array}$ & $\begin{array}{l}\text { Status and degree of success } \\
\text { with integrating M4R's key } \\
\text { principles, measurement of } \\
\text { outcomes and use of evidence } \\
\text { for adaptive management and } \\
\text { learning to drive results. } \\
\text { Developing M4R capacity }\end{array}$ & $\begin{array}{l}\text { Based primarily on a desk } \\
\text { review of project-level } \\
\text { evaluations and the limited } \\
\text { number of existing country } \\
\text { strategies since }\end{array}$ & IEG evaluation from 1998. \\
\hline $\begin{array}{l}\text { US Office of Foreign } \\
\text { Assistance at the } \\
\text { Department of State (US). } \\
\text { Evaluation of the Office of } \\
\text { U.S. Foreign Assistance } \\
\text { resources' implementation } \\
\text { of the managing for results } \\
\text { framework. } \\
\text { PwC Public Sector LLP }\end{array}$ & $\begin{array}{l}\text { To assess the effectiveness of } \\
\text { the Managing for Results } \\
\text { framework as it relates to the } \\
\text { management of FA programs } \\
\text { and resources. }\end{array}$ & $\begin{array}{l}\text { Review of Management for } \\
\text { Results (MfR) training, } \\
\text { guidance, communications as } \\
\text { well as management } \\
\text { documents and prior studies. } \\
\text { Electronic surveys, } \\
\text { stakeholder interviews, and } \\
\text { focus groups. Analysis of } \\
\text { MfR products from two } \\
\text { regional and two functional } \\
\text { bureaus. }\end{array}$ & \\
\hline SDC & $\begin{array}{l}\text { The relevance, effectiveness } \\
\text { and efficiency of SDC's RBM } \\
\text { System; a system covering }\end{array}$ & $\begin{array}{l}\text { Review of SDC RBM } \\
\text { documentation and processes. } \\
\text { Three field visits to Ukraine, }\end{array}$ & Short review in 2013. \\
\hline
\end{tabular}




\begin{tabular}{|c|c|c|}
\hline $\begin{array}{l}\text { Evaluation of SDC's } \\
\text { Results Based Management } \\
\text { System with a Focus on } \\
\text { Poverty Reduction. } 2017 . \\
\text { SPM Consultants }\end{array}$ & $\begin{array}{l}\text { most SDC management } \\
\text { processes from the corporate } \\
\text { to the project levels and all } \\
\text { domains. }\end{array}$ & $\begin{array}{l}\text { Rwanda and Bangladesh, } \\
\text { Two surveys for } 700 \text { staff, } 60 \\
\text { interviews and three e- } \\
\text { discussions. }\end{array}$ \\
\hline $\begin{array}{l}\text { CGIAR, Global } \\
\text { agricultural research } \\
\text { partnership } \\
\text { Evaluation of Results } \\
\text { Based Management in } \\
\text { CGIAR } \\
\text { Vanderberg R, Wigboldus } \\
\text { S }\end{array}$ & $\begin{array}{l}\text { To province evidence and } \\
\text { lessons as an input to } \\
\text { implementing RBM } \\
\text { framework. To formulate } \\
\text { recommendations for } \\
\text { increasing RBM relevance, } \\
\text { efficiency and effectiveness. }\end{array}$ & $\begin{array}{l}\text { Review from 2009-2017. } \\
\text { Examination of institutions } \\
\text { and actors across CGIAR } \\
\text { system. Examined drivers of } \\
\text { RBM, lessons from piloting } \\
\text { RBM, support for RBM and } \\
\text { experiences for optimising it. }\end{array}$ \\
\hline
\end{tabular}

Table 2. Other studies and reviews related to RBM

\begin{tabular}{|c|c|c|}
\hline $\begin{array}{l}\text { Organisation } \\
\text { Name of study } \\
\text { Author }\end{array}$ & Focus & Method: \\
\hline $\begin{array}{l}\text { EU } \\
\text { Analysis of Joint Results } \\
\text { Frameworks in EU Joint } \\
\text { Programming } \\
\text { Alexander O'Riordan } \\
\text { Katarina Courtnadge-Kovačević }\end{array}$ & $\begin{array}{l}\text { To inform and discuss current experience } \\
\text { in developing joint results frameworks } \\
\text { To assess to which extent data quality } \\
\text { mechanisms are active in the view of } \\
\text { formulating approaches how to best } \\
\text { engage in this process. }\end{array}$ & $\begin{array}{l}\text { Analysis of } 7 \text { country case studies, } \\
\text { interviews. Desk-review. }\end{array}$ \\
\hline $\begin{array}{l}\text { DFID } \\
\text { The politics of the results agenda in } \\
\text { DFID 1997-2017 } \\
\text { ODI }\end{array}$ & $\begin{array}{l}\text { Questions: What exactly is the results } \\
\text { agenda in the United Kingdom context? } \\
\text { Where did it come from? Why did it } \\
\text { emerge? How have people reacted? And } \\
\text { what can we learn from this experience? }\end{array}$ & Literature review. 60 interviews. \\
\hline $\begin{array}{l}\text { USAID } \\
\text { Evidence base for collaborating, } \\
\text { learning and adapting } \\
\text { Dexis Consulting Group }\end{array}$ & $\begin{array}{l}\text { Does an intentional, systematic and } \\
\text { resourced approach contribute to } \\
\text { organisational effectiveness or } \\
\text { development outcomes? Under what } \\
\text { conditions? How do we measure CLA } \\
\text { contributions to development results? }\end{array}$ & $\begin{array}{l}\text { A literature review to discover what } \\
\text { information exists in the peer-reviewed } \\
\text { and grey literature to answer the } \\
\text { questions above, as well as the methods } \\
\text { others have used to try to answer them. }\end{array}$ \\
\hline $\begin{array}{l}\text { Canada, Netherlands, New Zealand, } \\
\text { Sweden, Switzerland, United } \\
\text { Kingdom and the World Bank. } \\
\text { Strengthening the results chain: } \\
\text { Synthesis of case studies of results- } \\
\text { based management by providers. } \\
2017 . \\
\text { OECD/DAC }\end{array}$ & $\begin{array}{l}\text { Analysis of results-based management } \\
\text { approaches by development co-operation } \\
\text { providers. To identify and document key } \\
\text { themes, current challenges and good } \\
\text { practice in results-based management, } \\
\text { and to make use of this analysis to } \\
\text { encourage dialogue and drive collective } \\
\text { learning amongst the OECD/DAC } \\
\text { Results Community. }\end{array}$ & $\begin{array}{l}\text { Evidence from seven case studies } \\
\text { conducted by the OECD in 2016-17, } \\
\text { literature on results-based management of } \\
\text { development co-operation. Desk-based } \\
\text { review of materials (supplied by } \\
\text { providers) and phone interviews with } \\
\text { staff responsible for results at provider } \\
\text { headquarters. }\end{array}$ \\
\hline $\begin{array}{l}\text { Global Affairs Canada } \\
\text { Synthesis of Evaluations of Grants } \\
\text { and Contributions Programming } \\
\text { funded by the International } \\
\text { Development Assistance Envelope, } \\
\text { 2011-2016, } 2017 \\
\text { Universalia }\end{array}$ & $\begin{array}{l}\text { Identify lessons and recurring challenges } \\
\text { to inform future departmental } \\
\text { programming and foster horizontal } \\
\text { learning } \\
\text { Including. How well RBM tools are used } \\
\text { in programme evaluation }\end{array}$ & $\begin{array}{l}\text { Review of forty evaluation reports. } \\
\text { Review of how RBM tools were used in } \\
\text { the evaluation reports. }\end{array}$ \\
\hline $\begin{array}{l}\text { World Bank } \\
\text { Behind the Mirror - A Report on the } \\
\text { Self-Evaluation Systems of the } \\
\text { World Bank. } 2016\end{array}$ & $\begin{array}{l}\text { To support ongoing efforts to enhance } \\
\text { effectiveness, promote learning, foster the } \\
\text { move toward a "Solutions Bank," and } \\
\text { simplify processes. }\end{array}$ & Review of WBs self-evaluation systems \\
\hline
\end{tabular}




\begin{tabular}{|c|c|c|}
\hline IEG Independent Evaluation Group & & \\
\hline $\begin{array}{l}\text { Sida } \\
\text { Evaluation of the market systems } \\
\text { development approach - Lessons } \\
\text { for expanded use and adaptive } \\
\text { management at Sida. } 2018 \\
\text { Itad. }\end{array}$ & Forthcoming & \\
\hline $\begin{array}{l}\text { NORAD } \\
\text { The quality of Reviews and } \\
\text { Decentralised Evaluations in } \\
\text { Development Cooperation. } 2017 . \\
\text { Itad \& Chr. Michelsen Institute }\end{array}$ & $\begin{array}{l}\text { Assess the quality of reviews, } \\
\text { Examine the use of the review findings } \\
\text { Identify factors contributing to quality } \\
\text { and use }\end{array}$ & $\begin{array}{l}\text { Meta-evaluation: survey of grant } \\
\text { managers, quality assessment of } 60 \\
\text { reviews and TORs conducted in } 2014 \text {, } \\
\text { case studies from five of the reviews, } \\
\text { online survey of staff Norwegian MFA, } \\
\text { embassies and Norad. }\end{array}$ \\
\hline $\begin{array}{l}\text { USAID } \\
\text { Evaluation Utilization at USAID. } \\
2016 . \\
\text { Management Systems International }\end{array}$ & $\begin{array}{l}\text { To help USAID determine the extent to } \\
\text { which its evaluations are being used and } \\
\text { what guidance, tools, or Agency practices } \\
\text { might be improved to enhance evaluation } \\
\text { utilization }\end{array}$ & $\begin{array}{l}\text { Thorough document review, survey and } \\
\text { group interviews with USAID staff in } 24 \\
\text { Agency Operating Units in Washington } \\
\text { and overseas. Interviews with key } \\
\text { informants in USAID and nine partner } \\
\text { organisations that conduct evaluation for } \\
\text { USAID. }\end{array}$ \\
\hline $\begin{array}{l}\text { Six US Agencies in charge of } \\
\text { Development Cooperation } \\
\text { Agencies Can Improve the Quality } \\
\text { and Dissemination of Program } \\
\text { Evaluations.2017. } \\
\text { U.S Government Accountability } \\
\text { Office (GAO) }\end{array}$ & $\begin{array}{l}\text { The quality, cost, and dissemination of } \\
\text { foreign aid program evaluations. }\end{array}$ & $\begin{array}{l}\text { Assessed } 173 \text { FY2015 evaluations for } \\
\text { programs at the six agencies: USAID, } \\
\text { State, MCC, HHS's Centers for Disease } \\
\text { Control and Prevention under the } \\
\text { President's Emergency Plan for AIDS } \\
\text { Relief, USDA's Foreign Agricultural } \\
\text { Service, DOD's Global Train and Equip } \\
\text { program. Analysed cost and contract } \\
\text { documents; reviewed agency websites } \\
\text { and dissemination procedures. }\end{array}$ \\
\hline $\begin{array}{l}\text { Finland } \\
\text { Meta-evaluation of Project and } \\
\text { Programme Evaluations in 2015- } \\
\text { 2017. Evaluation on Finland's } \\
\text { Development Policy and } \\
\text { Cooperation (2018) } \\
\text { Ministry for Foreign Affairs }\end{array}$ & $\begin{array}{l}\text { To provide recommendations enabling } \\
\text { the MFA to enhance the quality of } \\
\text { decentralised evaluations, to improve } \\
\text { evaluation management practices and to } \\
\text { foster evaluation capacity development; } \\
\text { to provide insights from the evaluation } \\
\text { reports for recommendations on how to } \\
\text { improve development cooperation. }\end{array}$ & $\begin{array}{l}\text { A methodological quality assessment } \\
\text { using a standardised assessment tool (a } \\
\text { detailed checklist for } 51 \text { evaluation } \\
\text { reports and their Terms of References). }\end{array}$ \\
\hline $\begin{array}{l}\text { AFDB, African Development Bank } \\
\text { Evaluation of Quality Assurance at } \\
\text { the African Development Bank: } \\
\text { Promoting Accountability and } \\
\text { Learning for Development } \\
\text { Effectiveness } \\
\text { IDEV, Independent Development } \\
\text { Evaluation AFDB }\end{array}$ & $\begin{array}{l}\text { To follow up on known challenges with } \\
\text { respect to the quality of the Bank's } \\
\text { portfolio; } \\
\text { To address broader issues across the } \\
\text { project cycle, including the contribution } \\
\text { of the quality assurance chain to learning } \\
\text { and development effectiveness; and } \\
\text { To support the implementation, providing } \\
\text { an independent view and bringing } \\
\text { forward lessons. }\end{array}$ & $\begin{array}{l}\text { The evaluation has examine quality at } \\
\text { entry, supervision and at exit, including } \\
\text { how the safeguards system is integrated } \\
\text { into the Bank's quality assurance } \\
\text { processes over the project cycle. }\end{array}$ \\
\hline
\end{tabular}




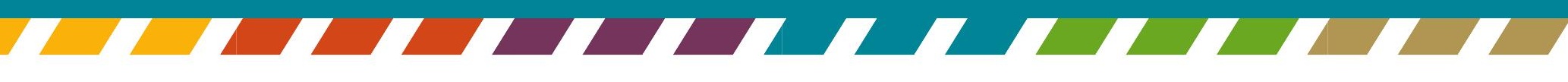

